\title{
Land Surface Energy and Moisture Fluxes: Comparing Three Models
}

\author{
J.-P. SCHUlZ AND L. DÜMENIL \\ Max-Planck-Institut für Meteorologie, Hamburg, Germany \\ J. POLCHER \\ Laboratoire de Météorologie Dynamique du CNRS, Paris, France \\ C. A. Schlosser \\ Geophysical Fluid Dynamics Laboratory/NOAA, Princeton, New Jersey \\ Y. XUE \\ Center for Ocean-Land-Atmosphere Studies, Calverton, Maryland
}

(Manuscript received 4 November 1996, in final form 20 June 1997)

\begin{abstract}
Three different land surface schemes that are designed for use in atmospheric general circulation models are compared. They were run in offline mode with identical atmospheric forcing values that were observed at Cabauw. This procedure allows one to analyze differences in the simulations that are not caused by different atmospheric conditions and to relate them to certain model characteristics. The intercomparison shows that the models produced similar results for surface temperature and total net radiation, which are also in good agreement with the observations. But they underestimate latent heat flux and overestimate sensible heat flux in summer. Differences in the components of energy and hydrological cycle as simulated by the schemes can be related to differences in model structures. The calculation of the surface temperature is of major importance, particularly on a diurnal timescale. Depending on the scheme chosen, the simulated surface temperature is closer to the observed radiative surface temperature or the observed soil temperature at a depth of a few centimeters. If a land surface scheme is going to be coupled to an atmospheric model, this needs to be considered. The simulation of the surface energy fluxes can be improved by careful calibration of the relevant parameters according to the conditions at the observational site. The stomatal resistance was found to be an essential parameter in determining the evolution of evapotranspiration for the Cabauw simulations.
\end{abstract}

\section{Introduction}

Land surface processes have a significant impact on near-surface climate phenomena. They determine, among other things, near-surface sensible and latent heat fluxes and the radiation budget, and thus influence atmosphere and land characteristics, such as temperature and humidity, cloud formation, and the entire structure of the planetary boundary layer. It is therefore important to simulate land surface processes in climate models as realistically as possible. The component of a general circulation model (GCM) responsible for this is the land surface scheme. When investigating the ability of a GCM to give realistic results for the surface variables such as soil temperature or surface fluxes, the problem

Corresponding author address: Jan-Peter Schulz, Max-Planck-Institut für Meteorologie, Bundestrasse 55, 20146 Hamburg, Germany. E-mail: jan.schulz@dkrz.de arises that these quantities are influenced by the performance of the land surface scheme as well as by the simulated atmospheric conditions. So the objective for the international projects SLAPS (Spatial Variability of Land Surface Processes) (Dooge et al. 1994; Polcher et al. 1996) and PILPS (Project for Intercomparison of Land-surface Parameterization Schemes) (HendersonSellers et al. 1993; Chen et al. 1997) was to compare different land surface schemes in off-line experiments; that is, the schemes are not allowed to interact with the atmosphere. This was done by using the same prescribed atmospheric conditions and surface parameters for all schemes. These atmospheric data were either derived from a GCM simulation or, as in PILPS, observed data were also used. This procedure allows one to compare the behavior of the various schemes and to examine the role of specific model characteristics, while excluding effects resulting from feedbacks with the atmosphere. The analyses of the comparison projects show that the schemes behave very differently. It is even difficult to 
a)

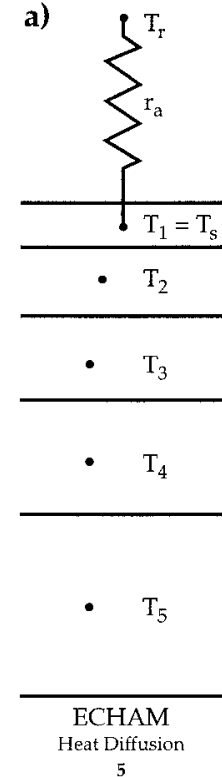

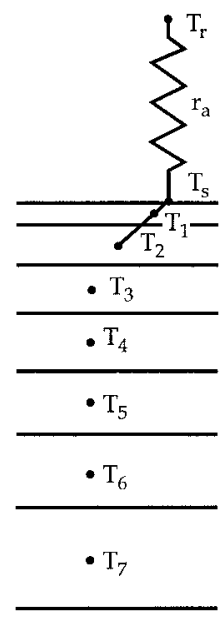

SECIHIBA Heat Diffusion

7

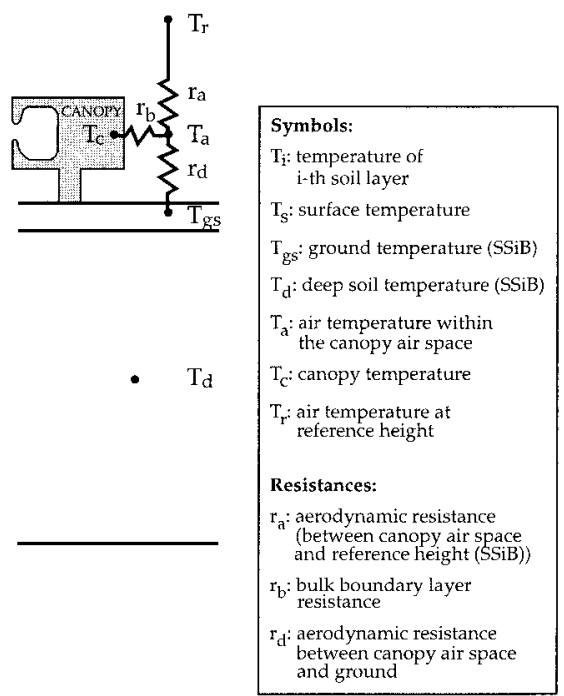

SSiB Force-Restore

$2 \quad$ layers for soil temperature

b)
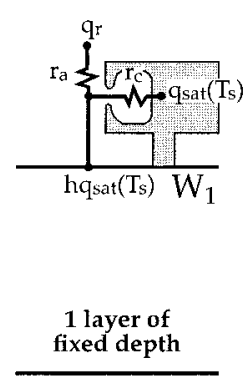

ECHAM

Bucket, Arno

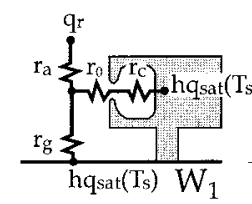

Layer of variable depth

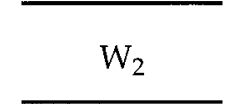

SECHIBA

Bucket, Choisnel

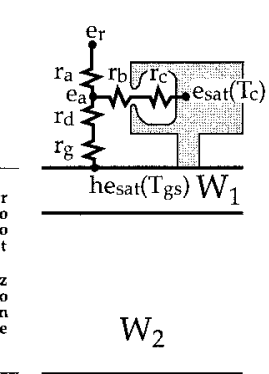

\begin{tabular}{l}
\hline $\mathbf{r}$ \\
$\mathbf{e}$ \\
$\mathbf{c}$ \\
$\mathbf{h}$ \\
$\mathbf{a}$ \\
$\mathbf{r}$ \\
$\mathbf{g}$ \\
$\mathbf{e}$ \\
$\mathbf{1}$ \\
$\mathbf{a}$ \\
$\mathbf{y}$ \\
$\mathbf{e}$ \\
$\mathrm{r}$ \\
\hline
\end{tabular}

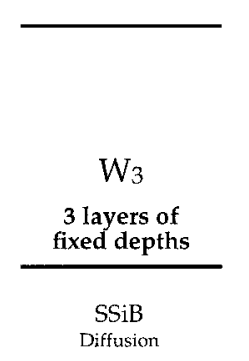

FIG. 1. Schematic representation of (a) the soil temperature layers and the resistances for the calculation of sensible heat fluxes and (b) the soil moisture layers and the resistances for the calculation of latent heat fluxes in ECHAM, SECHIBA, and SSiB.

separate the models into different classes of typical behavior (cf. Chen et al. 1997). We therefore focus on a comparison of a small number of schemes of a more or less similar degree of complexity but will examine them in more detail. For this study, the land surface schemes of the Max-Planck-Institut (MPI) für Meteorologie GCM (ECHAM), the Laboratoire de Météorologie Dynamique (LMD) GCM (SECHIBA), and the Simplified Simple Biosphere (SSiB) scheme were chosen (Roeckner et al. 1992; Ducoudré et al. 1993; Xue et al. 1991).
In addition, sensitivity experiments with the ECHAM model were performed, which investigate the effect of prescribed changes in land surface characteristics on the atmosphere and surface.

\section{The models}

Figure 1 gives a schematic overview of the three schemes to be compared. 


\section{a. ЕСНАM}

In the ECHAM model (Roeckner et al. 1992), the surface fluxes of momentum, heat, and moisture are calculated by means of the classical aerodynamic formulas using the Monin-Obukhov similarity theory:

$$
F_{X}=\rho C_{D}|\mathbf{v}|\left(X_{S}-X_{a}\right),
$$

where $\rho$ is the density of air, $C_{D}$ the drag coefficient for momentum or heat, and $|\mathbf{v}|$ the absolute value of the horizontal wind speed. The value of $X_{a}$ may be identified with the atmospheric value of one of the quantities which is subject to the turbulent exchange, while $X_{S}$ is its surface value. The drag coefficients are functions of roughness length and the Richardson number and are calculated by following Louis (1979). For evaluating the moisture flux over land, each grid square is divided into four fractions. These fractions are snow cover, water in the skin reservoir, vegetation, and bare soil. The moisture flux is calculated for every single fraction according to the following equation:

$$
E=\rho C_{h}|\mathbf{v}| \beta\left[h q_{s}\left(T_{S}, p_{S}\right)-q_{a}\right],
$$

where $q_{s}$ is the saturation specific humidity at surface temperature $T_{S}$ and pressure $p_{S}$, and $q_{a}$ is the atmospheric specific humidity at a reference level. The values of $\beta$ and $h$ have to be specified for each fraction. Snow sublimation and evaporation of water in the skin reservoir are assumed to be at the potential rate, that is, $\beta$ $=h=1$. Evaporation from bare soil is limited by the relative humidity $h$ at the surface, which is related to the soil moisture. For bare soil evaporation, $\beta=1$. Transpiration from vegetation is controlled by the stomatal resistance $r_{c}$ and the water stress factor $F\left(W_{s}\right)$, which describes the availability of water in the root zone. The value of $F$ is a function of the soil water content $W_{s}$. Based on Sellers et al. (1986), $\beta$ is specified as

$$
\beta=\left[1+\frac{C_{h}|\mathbf{v}| r_{c}(\mathrm{PAR})}{F\left(W_{S}\right)}\right]^{-1},
$$

and $r_{c}$ depends on the photosynthetically active radiation (PAR):

$$
\frac{1}{r_{c}}=\frac{1}{k c}\left[\frac{b}{d \mathrm{PAR}} \ln \left(\frac{d e^{k \mathrm{LAI}}+1}{d+1}\right)-\ln \left(\frac{d+e^{-k \mathrm{LAI}}}{d+1}\right)\right] \text {, }
$$

where $d=(a+b c) /(c$ PAR $), k=0.9$, leaf area index $(\mathrm{LAI})=1.3, a=2582.01 \mathrm{~J} \mathrm{~m}^{-3}, b=1.09 \mathrm{~W} \mathrm{~m}^{-2}, c$ $=110 \mathrm{~s} \mathrm{~m}^{-1}$ are used for the ECHAM PILPS simulations. $c /$ LAI represents the minimum value of $r_{c}$ when PAR is approaching infinity. For computing the transpiration component, $h$ in (2) is set to 1 . The total moisture flux is computed as the weighted average of the four components that are described above.

For the calculation of the soil temperature, the concept of heat diffusion is used. The heat conduction equation is solved for five layers over land and land ice, following Warrilow et al. (1986), with the possibility of an additional snow layer on top of the soil. The temperatures are representative for the middle of each soil layer. The first soil layer in ECHAM is $6.5 \mathrm{~cm}$ deep, the second $25.4 \mathrm{~cm}$. The upper boundary condition is defined by the net heat flux (radiative and turbulent) at the surface. The surface energy budget is described by the surface energy equation

$$
R_{\text {net }}-\mathrm{LE}-H-G=0,
$$

where $R_{\text {net }}$ is the total surface net radiation, LE the latent heat flux, $H$ the sensible heat flux, and $G$ the ground heat flux. The net radiation is given by

$$
R_{\mathrm{net}}=(1-\alpha) R_{\mathrm{sd}}+R_{\mathrm{ld}}-\epsilon \sigma T_{S}^{4},
$$

where $R_{\mathrm{sd}}$ and $R_{\mathrm{ld}}$ are the downward shortwave and longwave radiation, respectively. The temperature of the first soil layer is used as land surface temperature $T_{S}$ (if the snow height is below a critical value). Here, $\alpha$ is the surface albedo, $\epsilon$ is the thermal emissivity, and $\sigma$ is the Stefan-Boltzmann constant. At the lower boundary, a zero heat flux condition is prescribed.

The water budget within the soil is computed for one layer with a prescribed field capacity. The governing equation takes precipitation, snow melt, evapotranspiration, and runoff into account. Interception of precipition is treated using one canopy layer, the skin reservoir.

Surface runoff accounts for subgrid scale effects due to the heterogeneity within a grid area (Arno scheme, Dümenil and Todini 1992). It is assumed that the fraction $s / S$ of the grid area in which the storage capacity is less than or equal to an assigned value $w$ is given by

$$
\frac{s}{S}=1-\left(1-\frac{w}{w_{\max }}\right)^{B} .
$$

The value of $w_{\max }$ is the maximum storage capacity in the grid element, and $B$ is a structure parameter that is characteristic for the grid element. Its values range from 0.01 to 0.5 . Here, $B$ takes into account the slope of the terrain, where a value of 0.01 represents very flat terrain that will allow a large fraction of precipitation to infiltrate the soil, while values approaching 0.5 indicate steep terrain where surface runoff will be more efficient. The drainage rate is a linear function of the soil moisture if it is between 5\% and $90 \%$ of the field capacity. For higher values, the drainage rate behaves like a potential function. Infiltration does not occur if the soil is frozen.

In the sensitivity tests, five modified versions of the ECHAM land surface scheme have been used in this study. They are identical to the reference version ECHAM but with some key land surface parameters changed (see Table 1 and Fig. 2).

\section{b. $\operatorname{SSiB}$}

The parameterization of the SSiB model allows a detailed description of the land surface fluxes in the pres- 
TABLE 1. Comparison of the main characteristics of the different model versions of ECHAM used in the present study. It is $W_{\operatorname{lmx}}=$ $W_{\operatorname{lmax}}[(1$ - vegrat $)+$ vegratLAI $]$, where $W_{\operatorname{lmax}}$ is the maximum amount of water that can be held on one layer of leaf or bare ground, vegrat is the vegetation ratio, LAI is the leaf area index, and $W_{\operatorname{lmx}}$ is the maximum canopy water content. Here, $B$ is the structure parameter used in the runoff scheme, $c$ is a key parameter for calculating the stomatal resistance [cf. (4)], and $\lambda$ is the thermal conductivity in the soil. In the first five model versions of ECHAM, LAI and vegrat are set constant to their annual mean values. In the sensitivity test ECHVARI, these parameters follow their observed annual cycles, as shown in Fig. 2.

\begin{tabular}{llccccc}
\hline \hline \multicolumn{1}{c}{ Model } & \multicolumn{1}{c}{$B$} & $\begin{array}{c}W_{\operatorname{lmax}} \\
(\mathrm{mm})\end{array}$ & $c\left(\mathrm{~s} \mathrm{~m}^{-1}\right)$ & $\begin{array}{c}\lambda(\mathrm{W} \\
\left.\mathrm{K}^{-1} \mathrm{~m}^{-1}\right)\end{array}$ & LAI & vegrat \\
\hline ECHAM & 0.2 & 0.1 & 110.0 & 2.0 & 1.3 & 0.956 \\
ECHFLAT & 0.025 & 0.1 & 110.0 & 2.0 & 1.3 & 0.956 \\
ECHWL & 0.2 & 1.0 & 110.0 & 2.0 & 1.3 & 0.956 \\
ECHEVAP & 0.2 & 0.1 & 40.0 & 2.0 & 1.3 & 0.956 \\
ECHTEMP & 0.2 & 0.1 & 40.0 & 1.0 & 1.3 & 0.956 \\
ECHVARI & 0.2 & 0.1 & 40.0 & 1.0 & Vari. & Vari. \\
\hline
\end{tabular}

ence of different biome types. The model is described and extensively used in numerous studies (e.g., Xue et al. 1991; Xue and Shukla 1993). The basic feature of the parameterization is its representation of the transfer of heat, moisture, and momentum between the atmosphere and the vegetated surface of the earth using a resistance formulation. In analogy to Ohm's law, sensible and latent heat fluxes between canopy air space and canopy or canopy air space and ground, respectively, are calculated as follows:

$$
F_{X}=\frac{\text { potential difference }}{\text { resistance }} \sim \frac{\Delta X}{\sum_{i} r_{i}} .
$$

The value of $X$ may be identified with the temperature or vapor pressure. The fluxes are driven by $\Delta X$, the gradient of $X$ between canopy air space and canopy or ground, and are limited by a sum of resistances $r_{i}$, which may be aerodynamic and/or surface resistances. The formulations of the land surface fluxes as given by (8) and (1) can be converted into each other.

In the SSiB model, five components of the downward radiation flux through the lowest layer of the atmosphere are treated: direct beam and diffusive radiation in the visible and near-infrared wavelength intervals and diffusive thermal radiation. The surface albedo and the netabsorbed radiation at the canopy and at the ground are parameterized as functions of solar zenith angle and snow cover on the canopy and ground.

For the calculation of the ground and the deep soil temperature, the force-restore method is used. Additionally, a canopy temperature is computed.

For the interception of precipitation, one canopy water store is used. Infiltrated water may be stored in three soil layers. For the Cabauw simulations, their prescribed depths are $0.1,0.9$, and $9.0 \mathrm{~m}$ from top to bottom. Transfer of water between the layers is described by diffusion. In the Cabauw simulations, the roots of the vegetation can penetrate the two upper layers, called the root zone. The water content of these two layers may be reduced by transpiration. From the third layer, the recharge layer, water can be abstracted by gravitational drainage. A snow cover can appear on the canopy and ground.

\section{c. SECHIBA}

In SECHIBA (Ducoudré et al. 1993), the turbulent surface fluxes are also computed from a resistance formulation. Interception is treated using seven different types of canopies that may be present in one grid square. A difference to the other models is the formulation of the hydrological stress that limits the transpiration. In SECHIBA it is an exponential function of the ratio of the dry soil height above the top soil moisture reservoir and the total soil height. The evaporation of foliage water is controlled by the aerodynamic resistance and an architectural resistance, the latter representing the aerodynamic resistance between the leaves and the canopy top.

The soil temperature is computed similar to ECHAM, but using seven layers, the upper one being about twothirds as deep as in ECHAM. The exchange of heat between the layers is calculated using the heat conduction equation. In SECHIBA, the surface temperature is computed using the surface energy balance equation and the soil properties obtained by an extrapolation of heat capacity and ground heat flux toward the surface.

The soil water is stored in two layers. The depths of the soil moisture layers in the two other models are fixed, while in SECHIBA, the upper layer has a variable depth (Choisnel scheme). This is designed to allow a fast response of the evaporation to precipitation events.

\section{The Cabauw observational data and the experiments}

The basic idea of this model intercomparison is to use equivalent parameter values for soil and vegetation of every land surface scheme and to force them with the same atmospheric values. By this procedure, the results of the simulations should only reveal similarities and differences of the model structures while excluding differences induced by feedback with the atmosphere or the choice of different parameter values. This study does not attempt to assess the quality of the land surface schemes. For this task, several datasets would have to be used representing different climatological situations. This comparison shall only give a general idea about the features, properties, and sensitivities of the models.

The Cabauw site is located in the center of the Netherlands. The flat terrain is almost completely covered with grass so that the vegetation ratio is nearly equal to 1 . This means that the soil water is almost exclusively extracted by transpiration and not by bare soil evaporation. Details about the measuring program at Cabauw are given by Driedonks et al. (1978). The set of obser- 

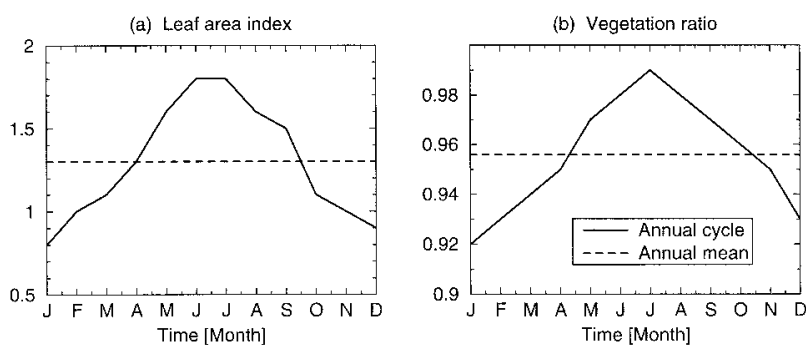

FIG. 2. Annual cycles of (a) leaf area index and (b) vegetation ratio as observed at Cabauw (given by the PILPS instructions).

vational data includes the meteorological quantities that are used as atmospheric forcing to drive the land surface schemes, that is, solar and thermal downward radiation, precipitation, horizontal wind components, air temperature, and specific humidity. As shown in Fig. 3, radiation, temperature, and humidity undergo a marked annual cycle with a maximum in summer; the wind speed has a maximum in winter. For precipitation, no annual cycle is obvious. For validation, measurements of sensible and latent heat fluxes, total net radiation, surface ground heat fluxes, and soil temperature are available. The observations cover 1 year at a time resolution of $30 \mathrm{~min}$. It must be noted that the three schemes were all forced with the observational data at a 30-min time step. In Fig. 3, the daily mean values were smoothed applying a 31-day running mean with periodic boundary conditions. The same procedure has been applied in most other figures in this study showing annual cycles of certain quantities. This was done only for the sake of clarity of the figures.

Studies of the data accuracy (Beljaars and Bosveld 1997) have shown that some observed quantities of the surface energy balance were seriously biased. Therefore, while the forcing variables of the PILPS Cabauw experiment have been extracted from an earlier version of the Cabauw data (Beljaars and Viterbo 1994), the energy fluxes for model validation were derived from a version of the Cabauw data that includes bias corrections (Beljaars and Bosveld 1997). The same procedure as described above was also applied to the Cabauw data by Chen et al. (1997) for the model intercomparison in PILPS. According to Chen et al. (1997), the remaining minor inconsistencies between the forcing and the validation data can be tolerated.

Parameters such as roughness length, leaf area index (LAI) and albedo, and the initial values of the moisture reservoirs and temperatures were prescribed for all schemes in a consistent way. The third soil moisture layer of $\mathrm{SSiB}$, the recharge layer, was set to saturation during the entire period of simulation. More details are given in Chen et al. (1997). Each model was run for a few years applying the 1-yr forcing dataset repeatedly until equilibrium was reached.

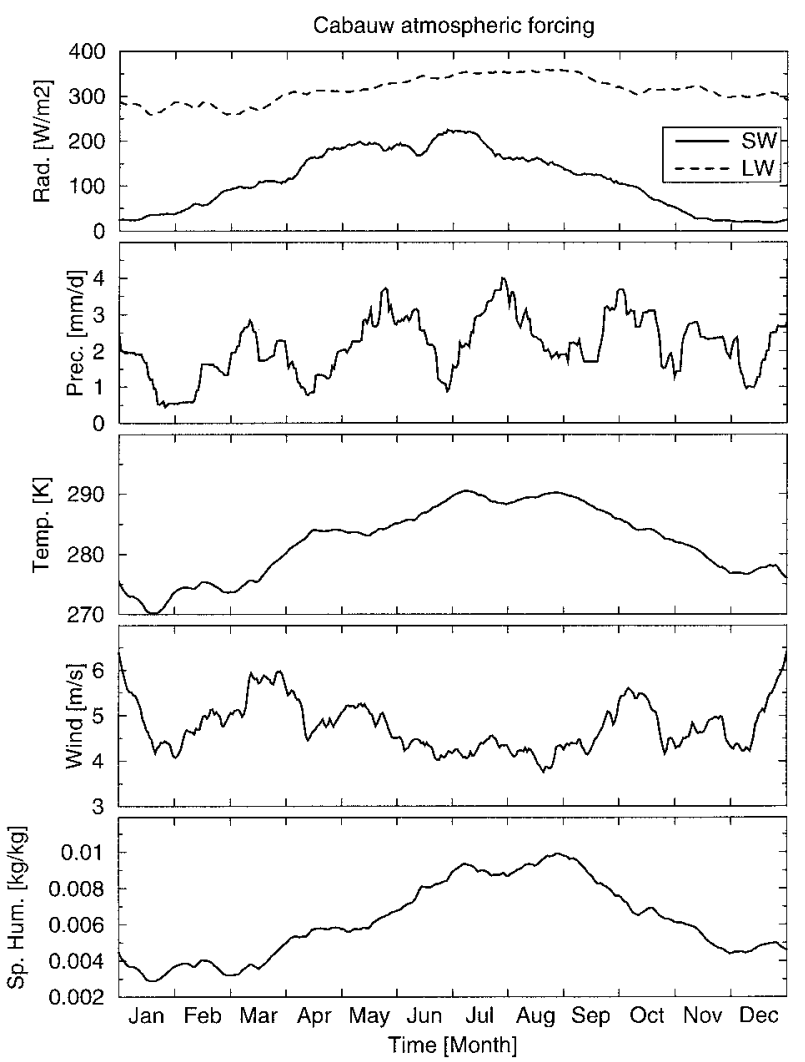

FIG. 3. Annual cycles of the Cabauw observational atmospheric forcing quantities, that is, shortwave (SW) and longwave (LW) radiation (Rad.), precipitation (Prec.), atmospheric temperature (Temp.), absolute wind speed (Wind), and atmospheric specific humidity (Sp. Hum.). The three schemes were all forced with the observational data at a 30 -min time step. For the clarity of the figure, the curves were smoothed using a 31-day running mean.

\section{Results}

\section{a. Model intercomparison}

\section{1) Surface EnERgy balance}

Figure 4 shows the annual cycle of the surface radiative temperature simulated by the individual models and also the observed surface radiative (effective) temperature $T_{\text {eff }}$ and the soil temperature $T_{S^{2}}$ measured at a depth of $2 \mathrm{~cm}$. Here, $T_{\text {eff }}$ is calculated from the observed upward longwave radiation. All curves show a clear seasonal variation with a minimum in January and a maximum in July. The value of $T_{\text {eff }}$ is less than that of $T_{S^{2}}$ during the whole year. The difference is in the range from 1 to $5 \mathrm{~K}$. The three model surface temperatures are very close to each other and their curves are within the range of the two observed temperatures almost over the entire year. This behavior is also represented by the annual mean temperature values that are $280.3 \mathrm{~K}$ for $T_{\text {eff }}, 283.5 \mathrm{~K}$ for $T_{S^{2}}, 282.0 \mathrm{~K}$ for ECHAM, 282.1 $\mathrm{K}$ for SECHIBA, and $281.8 \mathrm{~K}$ for SSiB. These simulated temperatures are all within the range between the observed $T_{\text {eff }}$ and $T_{S^{2}}$. 


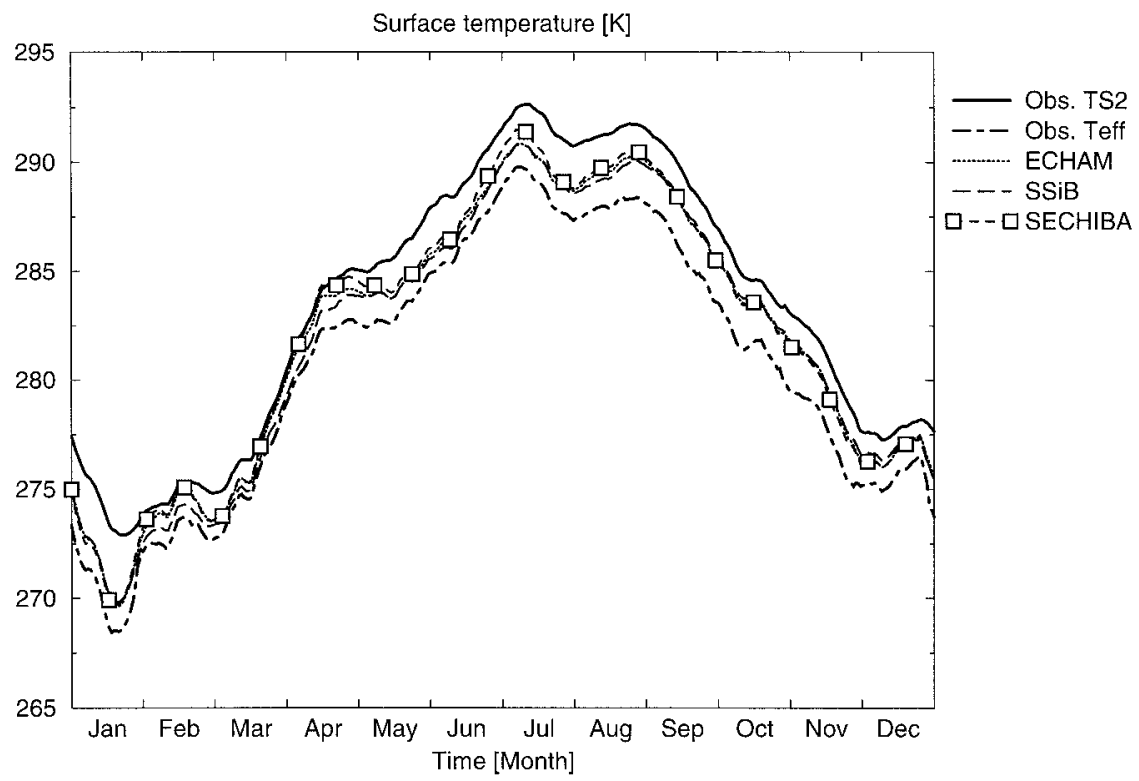

FIG. 4. Annual cycles of soil temperature $T_{S^{2}}$ measured at a depth of $2 \mathrm{~cm}$ and observed surface radiative (effective) temperature $T_{\text {eff }}$ compared to the model results of ECHAM, SSiB, and SECHIBA. The observations were made at Cabauw. The curves were smoothed using a 31-day running mean.

To better understand these results, we shall discuss the diurnal variations of the temperatures. An example for this is given in Fig. 5, which shows the diurnal variations of the surface temperature from 15 to 19 September, as observed at Cabauw and as simulated by ECHAM, SSiB, and SECHIBA. The diurnal cycles of the three model surface temperatures are very similar.
But there is the tendency that the characteristic shape of the diurnal temperature curve of ECHAM is closer to $T_{S^{2}}$ than that of the other models. This can be explained by a thermal damping of ECHAM's top soil layer which will be discussed in the following text.

As the ECHAM model soil temperatures are representative for the middle of each soil layer, the temper-

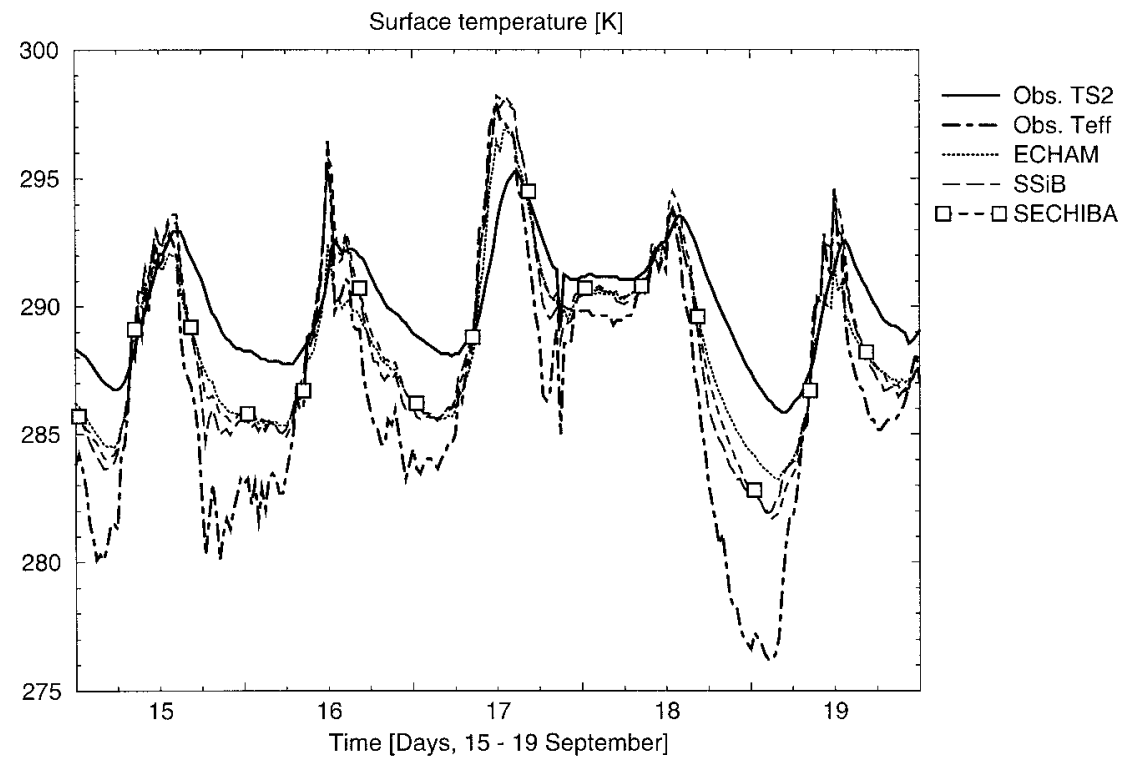

FIG. 5. Diurnal cycles of soil temperature $T_{S^{2}}$ measured at a depth of $2 \mathrm{~cm}$ and observed surface radiative (effective) temperature $T_{\text {eff }}$ from 15 to 19 September compared to the surface temperatures as simulated by ECHAM, SSiB, and SECHIBA. The observations were made at Cabauw. 


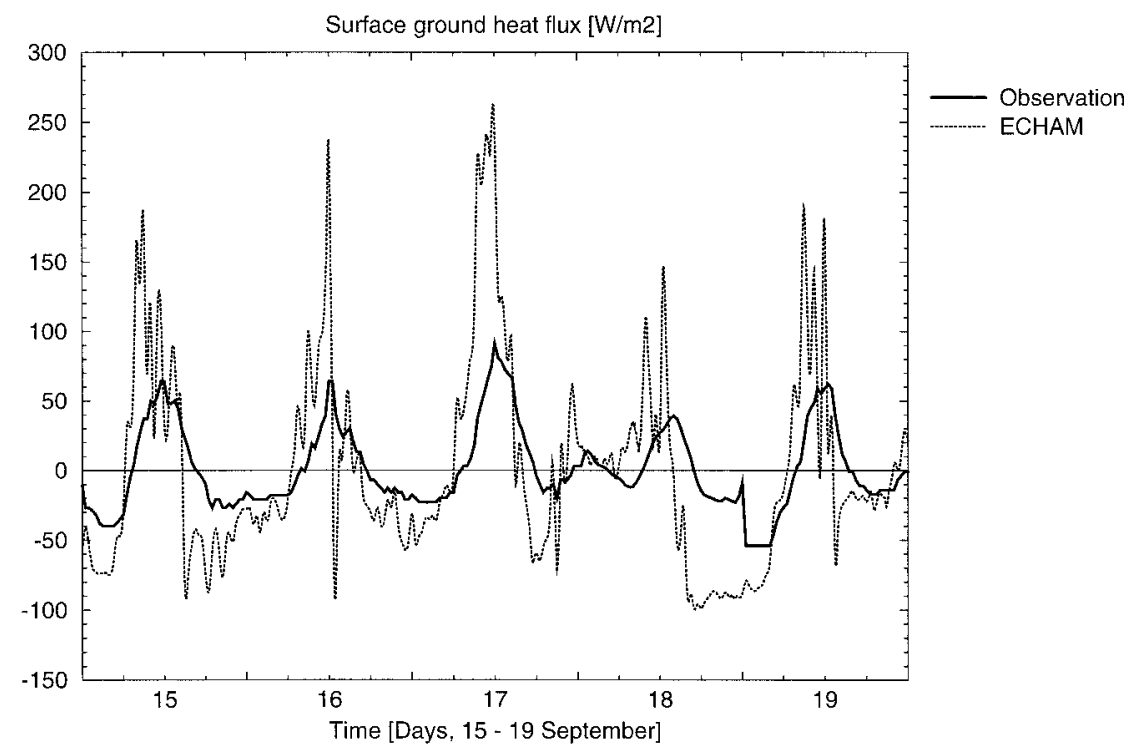

FIG. 6. Diurnal cycles of surface ground heat flux as observed at Cabauw from 15 to 19 September compared to the model results of ECHAM.

ature $T_{1}$ of the top layer, which is $6.5 \mathrm{~cm}$ deep, is expected to be comparable with the measured value at a depth of $3.25 \mathrm{~cm}$ (cf. Fig. 1a). The amplitudes of the diurnal soil temperature variation decrease with depth due to the heat conduction (diffusion) process in the soil. Additionally, there is a phase delay of the temperature signal with depth. Therefore, the amplitude of the diurnal variations of the ECHAM model temperature is expected to be smaller than that of $T_{S^{2}}$ but, as seen in Fig. 5, it is larger instead. The temperature curve is within the range of $T_{S^{2}}$ and $T_{\text {eff }}$ almost all the time. This behavior is mainly due to the discrepancy in the model that the first model layer temperature $T_{1}$ represents the soil temperature at a depth of $3.25 \mathrm{~cm}$ according to the soil heat conduction scheme; on the other hand, it is also used as surface temperature for computing the atmospheric energy fluxes. [Thermal upward radiation and sensible and latent heat fluxes are computed using $T_{1}$ as land surface temperature-see Fig. 1a and (1), (2), and (6).] But in reality, the relevant surface temperature for these energy fluxes is the one that is "seen" by the atmosphere at the soil-vegetation-atmosphere interface. With regard to the thermal upward radiation, this is $T_{\text {eff }}$. And for the turbulent energy fluxes, this is also not $T_{1}$. This aspect of the model parameterization leads to some problems.

This may be explained using the diurnal evolution of surface temperature on 17 September as an example (cf. Fig. 5). During the night from 16 to 17 September, $T_{\text {eff }}$ and ECHAM's $T_{1}$ both decrease to a minimum value, but the minimum of $T_{\text {eff }}$ is lower. In the early morning hours, both begin to rise because of the incoming solar radiation. According to the model structure, ECHAM cannot represent a "skin temperature," therefore it rises more slowly than $T_{\text {eff }}$. This "thermal inertia of the sur- face layer" was also found by Betts et al. (1993) with a Cycle 39 version of the ECMWF model. Therefore, the ECHAM model temperature is below $T_{\text {eff }}$ from about 0700 to 1200 UTC. As ECHAM's temperature is used to compute thermal upward radiation and sensible and latent heat fluxes, these atmospheric energy fluxes are underestimated in the morning. The residual energy in the model has to go into the ground, which leads to a highly overestimated surface ground heat flux in the model as compared to the observation (cf. Fig. 6). The model shows a peak of about $260 \mathrm{~W} \mathrm{~m}^{-2}$ in ground heat flux on 17 September, while a peak of only about 60 $\mathrm{W} \mathrm{m}{ }^{-2}$ was observed. As a consequence of the overestimated ground heat flux, the amplitude of the diurnal variations of the simulated soil temperature is overestimated. This is the reason why the temperature of the first soil layer in ECHAM, which is expected to represent the temperature at a depth of $3.25 \mathrm{~cm}$, shows a too-high diurnal amplitude, which is even significantly higher than the one observed at a depth of $2 \mathrm{~cm}\left(T_{S^{2}}\right)$. In the cooling phase during the second half of the day, the processes described above are reversed. This causes an overestimation of the negative ground heat flux (cf. Fig. 6).

In SECHIBA, the first soil layer is only $4.3 \mathrm{~cm}$ deep, and the second is $12.9 \mathrm{~cm}$ deep. But the surface temperature at the soil-atmosphere interface is computed using the surface energy balance equation and the soil properties obtained by an extrapolation of heat capacity and ground heat flux toward the surface. This procedure increases the dependence of surface temperature on atmospheric conditions by decreasing the effective heat capacity used in the surface energy balance equation. We would therefore expect the simulated surface temperature to be closer to the observed $T_{\text {eff }}$ than the tem- 


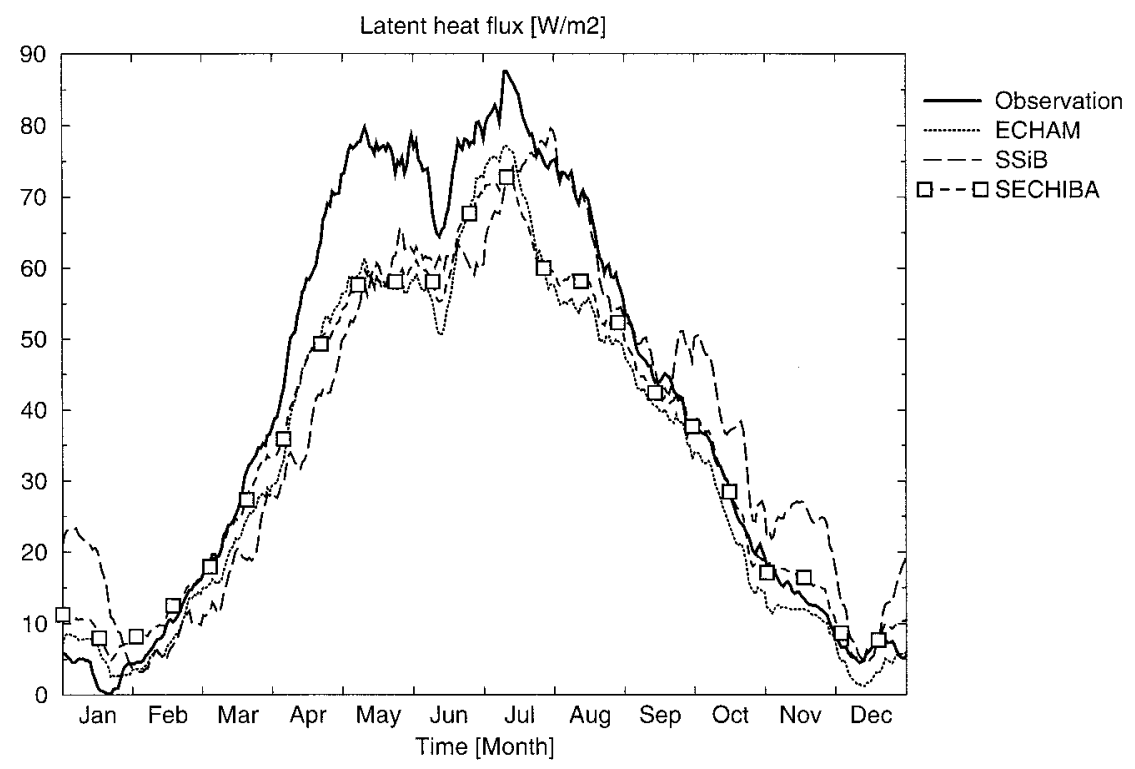

FIG. 7. Annual cycle of latent heat flux as observed at Cabauw compared to the model results of ECHAM, SSiB, and SECHIBA. The curves were smoothed using a 31-day running mean.

perature of the first layer that is computed in the middle of the layer.

In $\mathrm{SSiB}$, surface radiative temperature is an average of canopy temperature and the upper ground temperature, the latter of which is calculated by the force-restore method. It represents the region in the soil that is influenced by the diurnal temperature wave. These are typically the top $10 \mathrm{~cm}$ (cf. Hillel 1982). This is of the same order as in the other two models. But by taking into account the lower heat capacity of the canopy, SSiB should be able to follow more closely the diurnal variations of the surface radiative temperature under vegetated conditions.

In fact, during the evening hours of 15,16 , and 18 September, $\mathrm{SSiB}$ better reproduces a faster decrease of surface temperature, which is seen in the evolution of $T_{\text {eff }}$ (cf. Fig. 5), than ECHAM. At midday on 16 and 17 September, and during the nighttime minimum on 19 September, SSiB and SECHIBA are very similar. Due to their model structures, these schemes show less damping of the diurnal surface temperature variations than ECHAM. So the simulated surface temperatures of all three schemes are consistent with their model structures. None of them is able to exactly match the evolution of the observed radiative temperature that would be necessary, for example, for a realistic computation of the thermal upward radiation (see also section $4 \mathrm{~b}$ ).

Now let us consider the total net radiation $R_{\text {net }}$ that is given by (6). From the variables and parameters in this equation, only the surface temperature $T_{S}$ is computed by the models. The downward radiation components are part of the atmospheric forcing, and $\epsilon$ and $\sigma$ are constants. In ECHAM and SECHIBA, the albedo $\alpha$ is set to the Cabauw estimated value 0.25 (in the absence of snow). In $\mathrm{SSiB}, \alpha$ is predicted every time step with diurnal variation, but the daily mean surface albedo is constrained to be close to 0.25 . Here, $R_{\text {net }}$ has a distinct seasonal cycle with a minimum of $-20 \mathrm{~W} \mathrm{~m}^{-2}$ on the basis of the 31-day running mean in January and a maximum of $120 \mathrm{~W} \mathrm{~m}^{-2}$ in July representing the solar forcing (not shown). The observed annual mean value is $39.2 \mathrm{~W} \mathrm{~m}^{-2}$, the simulated values are $38.1 \mathrm{~W} \mathrm{~m}^{-2}$ for ECHAM, $37.4 \mathrm{~W} \mathrm{~m}^{-2}$ for SECHIBA, and $38.5 \mathrm{~W} \mathrm{~m}^{-2}$ for $\mathrm{SSiB}$. The model curves are very close to each other and are also in good agreement with the Cabauw observations during most of the year. The models underestimate the net radiation by up to $10 \mathrm{~W} \mathrm{~m}^{-2}$ during some periods in May, June, and July and from September to January. This is consistent with the simulated surface temperatures that are up to $2 \mathrm{~K}$ higher than the observed $T_{\text {eff }}$. Higher surface temperature causes enhanced upward longwave radiation, and the result is a decreased total net radiation if the other radiation components are fixed. The same behavior is shown by the three models also on a diurnal timescale (not shown). Similar results were found by Betts et al. (1993).

Figure 7 illustrates the seasonal cycles of observed and modeled latent heat fluxes. The observation shows a minimum in January and two maxima in May and July. The three models roughly reproduce this evolution, but they underpredict the latent heat flux in spring and summer. ECHAM shows an underprediction over the entire year except January, SECHIBA in the months from April to August, and SSiB from February to August. But from September to January, SSiB simulates a too-high evaporation. SECHIBA also allows for a small overprediction in winter except in December. Underestimation by the models in spring and summer amounts 


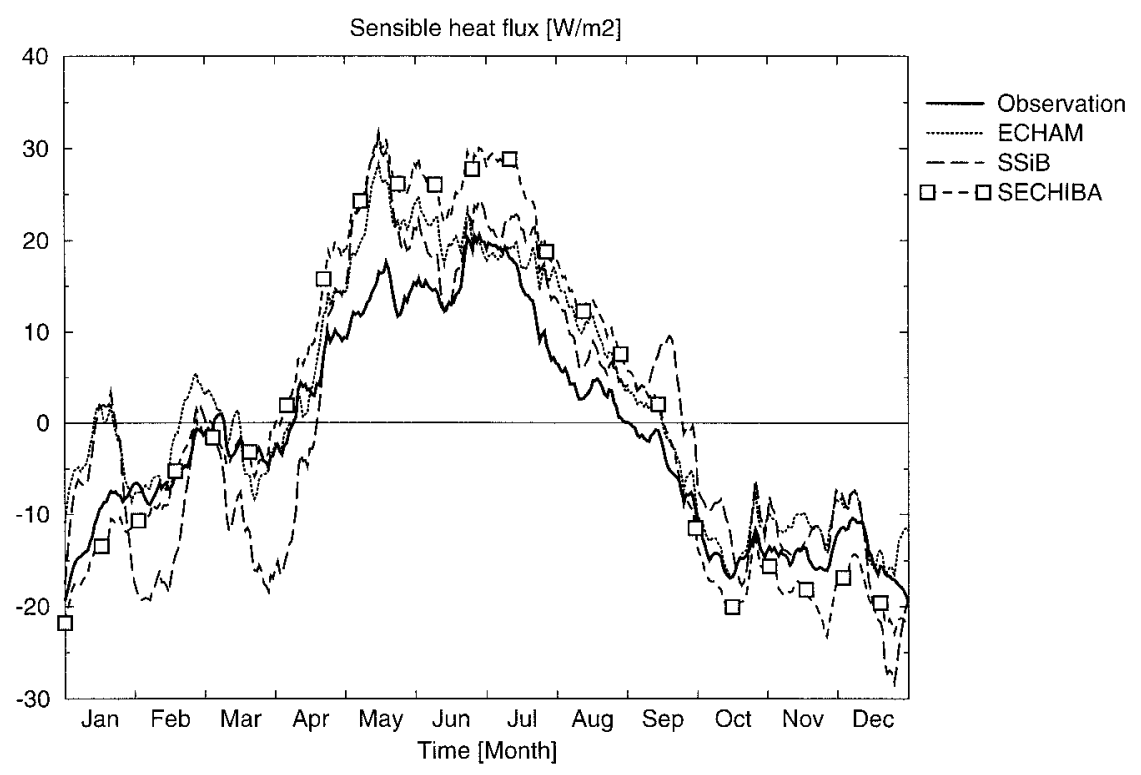

FIG. 8. As in Fig. 7 but for sensible heat flux.

to up to $20 \mathrm{~W} \mathrm{~m}^{-2}$. This is also represented by the annual means of latent heat flux that is $40.5 \mathrm{~W} \mathrm{~m}^{-2}$ for the observation and $38.0 \mathrm{~W} \mathrm{~m}^{-2}$ for $\mathrm{SSiB}$, followed by 35.7 $\mathrm{W} \mathrm{\textrm {m } ^ { - 2 }}$ for SECHIBA, and $33.3 \mathrm{~W} \mathrm{~m}^{-2}$ for ECHAM.

SECHIBA and ECHAM are in agreement with each other and in good agreement with the observations concerning the phase of the annual cycle of latent heat flux. They show a maximum in May-June, which is followed by a coincident local minimum in the middle of June and a second maximum in July. SSiB's latent heat flux evolves differently. There is no local minimum in the middle of June, but 2 weeks later, and the second summer maximum is also delayed by more than 2 weeks. From the comparison to the annual cycle of sensible heat flux, (Fig. 8) it becomes clear that SSiB's missing local minimum in latent heat flux in the middle of June is balanced by the sensible heat flux. Figure 8 shows a local minimum of sensible heat flux predicted by SSiB at that time that is less pronounced in the other model simulations or the observations.

The sensible heat flux is negative in winter and positive in summer. The models tend to be close to the observations in the months from October to April, but their behavior is different. For instance, from January to April ECHAM and SSiB show some variations, and $\mathrm{SSiB}$ is somehow oscillating around the observation; on the other hand, SECHIBA agrees very well with it during this period. All three schemes overestimate the sensible heat flux during the summer months from May to September by up to $20 \mathrm{~W} \mathrm{~m}^{-2}$. The observed annual mean is $-1.3 \mathrm{~W} \mathrm{~m}^{-2}$. ECHAM computes the highest annual mean at $2.6 \mathrm{~W} \mathrm{~m}^{-2}$ followed by SECHIBA with $1.6 \mathrm{~W} \mathrm{~m}^{-2}$ and then $\mathrm{SSiB}$ with $0.4 \mathrm{~W} \mathrm{~m}^{-2}$.

From these considerations it becomes clear that the models show deficiencies in estimating the partitioning of the net radiation into latent and sensible heat flux that is most obvious in the summer. In this period, the models show a systematic trend to underestimate latent heat flux and overestimate sensible heat flux. In the summer months, ECHAM and SECHIBA behave similarly concerning the phase of variations of latent and sensible heat flux. SSiB shows a different phase, most obvious in latent heat flux. This distinctly different behavior of the models is partly due to the different model structures applied to the surface moisture fluxes. This will be discussed in the next section.

\section{2) Surface WATER BALANCE}

Figure 9 shows the annual evolution of the relative plant-available soil moisture in the root zone as computed by the different schemes. For the calculation of this variable, we first subtract the wilting level from the root zone soil water content, as simulated by the models and from the field capacity, and then divide both quantities by each other. This means if the relative plantavailable soil moisture is $0 \%$, then the soil is at the wilting level (i.e., there is still moisture stored in the soil that is unavailable to plants). A relative soil moisture of $100 \%$ means that the soil is at field capacity. For the bucket-type models, ECHAM and SECHIBA, the field capacity is taken as the maximum soil water content. For SSiB, the maximum value is the total saturation. This allows relative soil moisture values of more than $100 \%$ for SSiB. ECHAM and SECHIBA simulate annual cycles of soil moisture with maxima in January of more than $97 \%$ for ECHAM and $100 \%$ for SECHIBA and minima in July of about $36 \%$ and $68 \%$, respectively. SSiB's relative soil water content stays in the range between about $98 \%$ and $119 \%$ throughout the 


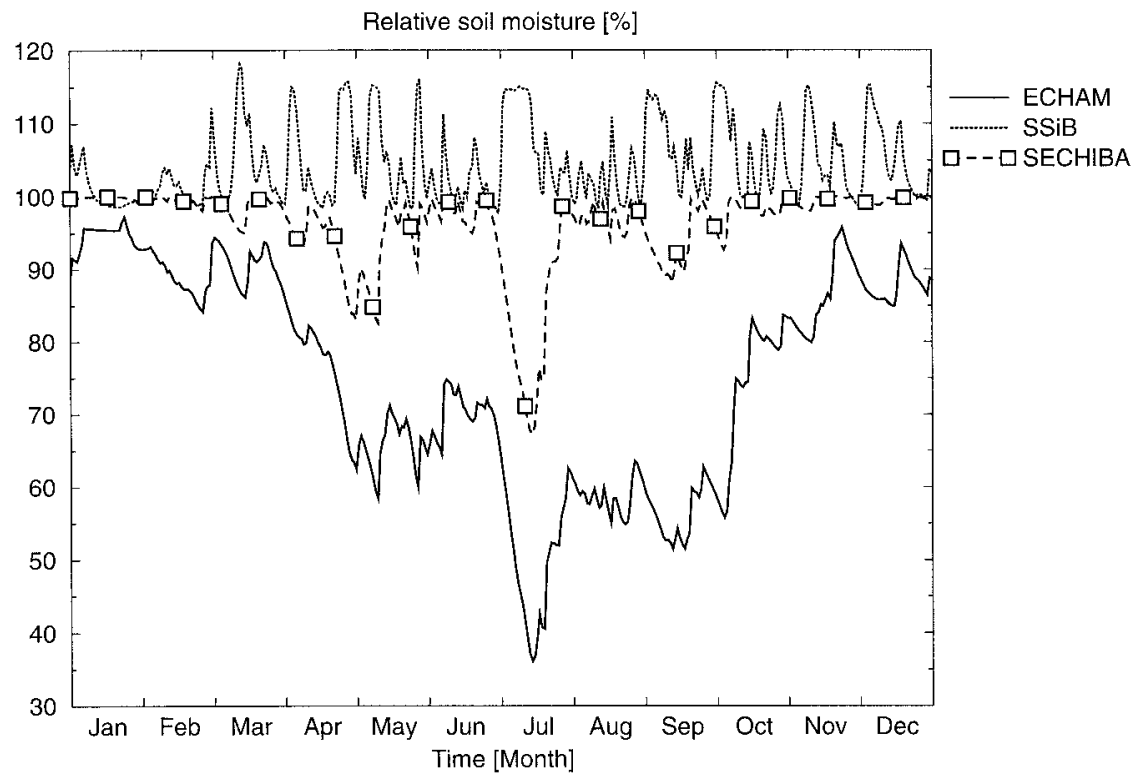

FIG. 9. Annual cycles of relative plant-available soil moisture in the root zone for ECHAM, $\mathrm{SSiB}$, and SECHIBA. Shown are unsmoothed daily means.

year without showing an annual cycle. This was expected because the lowest soil layer was set to total saturation at every time step (cf. Chen et al. 1997), and this prohibits any rapid downward transport of soil water from the upper layers and acts as a restoring reservoir when the soil water in the upper layers is depleted by evapotranspiration. The annual mean relative plantavailable soil moisture is highest in SSiB with $104.4 \%$ followed by SECHIBA with $96.1 \%$ and ECHAM with $75.1 \%$
Figures 10 to 12 show the annual cycles of precipitation; evapotranspiration; root zone drainage; and surface runoff for the ECHAM, SECHIBA, and SSiB models. The data were smoothed using a 31-day running mean. The precipitation is part of the atmospheric forcing that was used to drive the schemes and is therefore the same for each model. Precipitation is frequent during the whole year with an annual total of $776 \mathrm{~mm}$. The maximum rainfall rate is $4 \mathrm{~mm}$ day $^{-1}$ when filtered with a 31-day running mean. Daily mean values reach up to

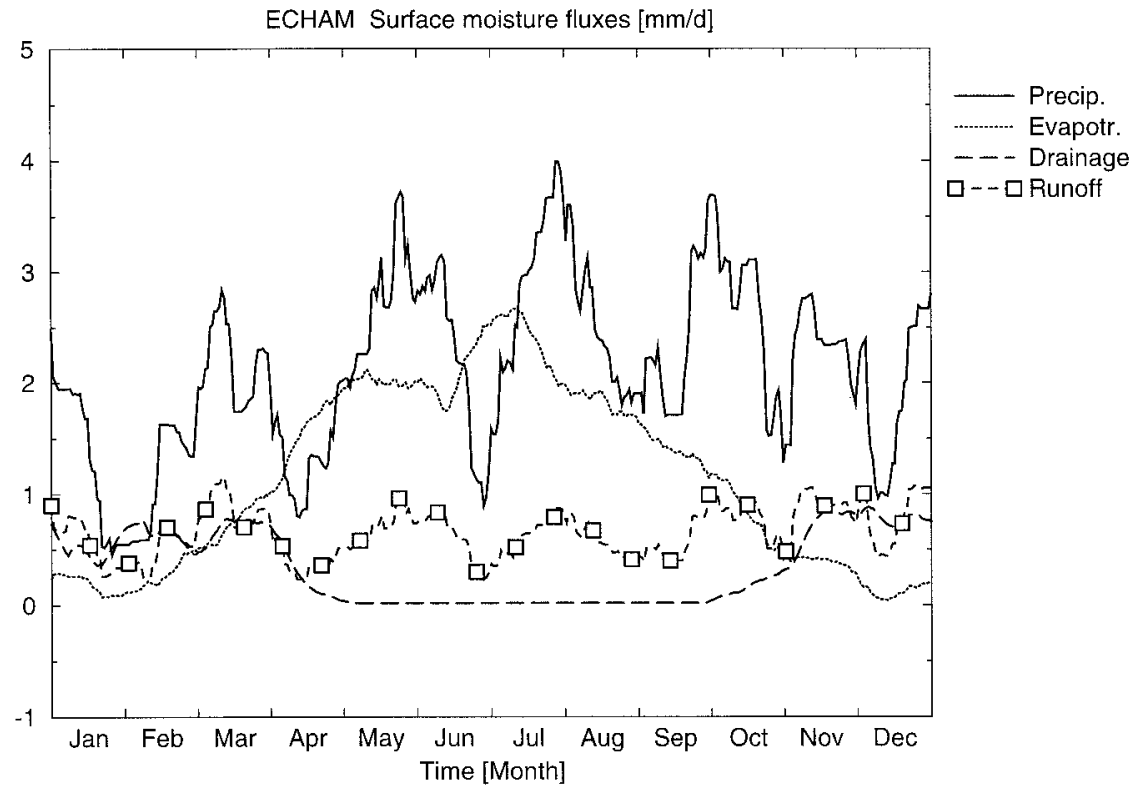

FIG. 10. Annual cycles of precipitation, evapotranspiration, root zone drainage, and surface runoff for ECHAM. The curves were smoothed using a 31-day running mean. 


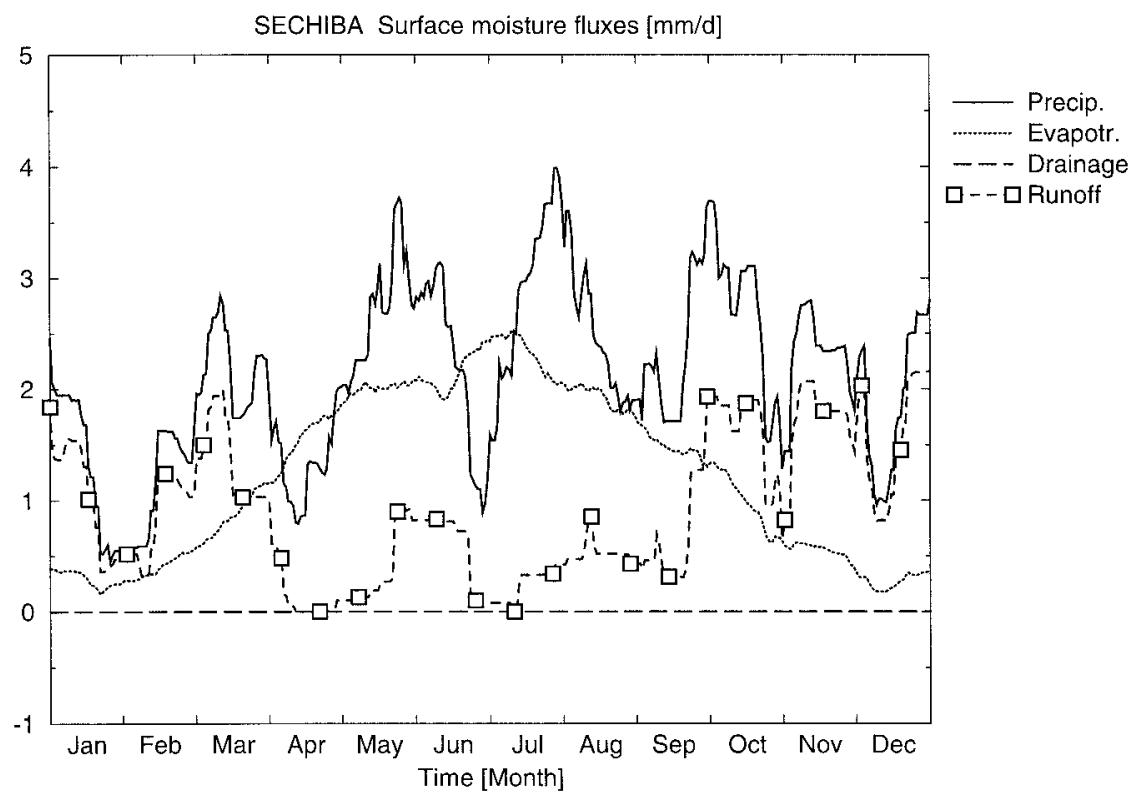

FIG. 11. As in Fig. 10 but for SECHIBA.

$23 \mathrm{~mm}$ day $^{-1}$. The three other quantities were simulated by the models.

Let us consider the surface moisture fluxes in ECHAM (Fig. 10). There is a close correspondence of surface runoff to precipitation regarding the phase. If there is high or low precipitation, there is also enhanced or reduced runoff, respectively. The amplitude of runoff depends on precipitation rate and soil moisture. The Arno scheme, which is used in ECHAM, allows saturation of the soil to occur in parts of a grid square. The higher the soil water content, the larger the fraction of saturated area and the higher the part of precipitation that will go into surface runoff. This is reflected in Fig. 10. The ratio of runoff to precipitation is higher in March than in May-June, for instance. The reason is that in March, the soil water content is higher than in May-June (Fig. 9).

The drainage rate is substantial from October to April. During the rest of the year, it is almost zero. In ECHAM, drainage rises linearly with the plant-available soil moisture between $0 \%$ and $75.7 \%$. These are empirical threshold values. Above the $75.7 \%$ level, drainage rises rapidly as a potential function. So the drainage rate is consistent with the evolution of soil moisture content that drops below 75.7\% in April and exceeds this value again in October (Fig. 9). Observations of the root zone drainage at Cabauw are not available. Typical drainage rates observed at other sites are $0.6 \mathrm{~mm} \mathrm{day}{ }^{-1}$ in the Vindelälven catchment that was derived from meteorological observations (Hagemann and Dümenil 1996) and 0.5 to $0.8 \mathrm{~mm} \mathrm{day}^{-1}$ in the catchments of Bothnian Bay and Bothnian Sea in winter (S. Hagemann 1996, personal communication; data provided by Carlsson).
There is a good agreement with the ECHAM simulations at Cabauw (Fig. 10).

A comparison of Figs. 10 and 3 shows that the annual variations of evapotranspiration in ECHAM closely follow that of solar radiation.

Figure 11 shows the surface moisture fluxes of SECHIBA. The runoff has a similar phase relation to precipitation to ECHAM. But the amplitude has an annual cycle that is much more pronounced than in ECHAM. During the months from November to March, a high part of the precipitation runs off. The reason is that in this period of time, the soil moisture is close to its maximum value (Fig. 9), so very little water can infiltrate. In April, the first half of May, and in July, runoff is lower than in ECHAM. In the second half of May, and in June and August, runoff is similar to ECHAM. These changes are due to the infiltration excess formulation of runoff in SECHIBA. In April-May and July, soil moisture is reduced in both models because of decreased precipitation and simultaneously increasing evapotranspiration. The Arno scheme in ECHAM still produces substantial runoff in this situation, as previously discussed. But in SECHIBA, soil moisture has to reach its maximum again before runoff is produced by infiltration excess. So ECHAM's surface runoff in summer closely follows the phase of precipitation, while the onset of the runoff in SECHIBA is a bit delayed due to the runoff scheme.

Due to the formulation of the Choisnel scheme, SECHIBA has no root zone drainage. Similar to ECHAM, the evolution of evapotranspiration is mainly determined by the amount of incoming solar radiation.

It cannot be decided whether the surface water bal- 


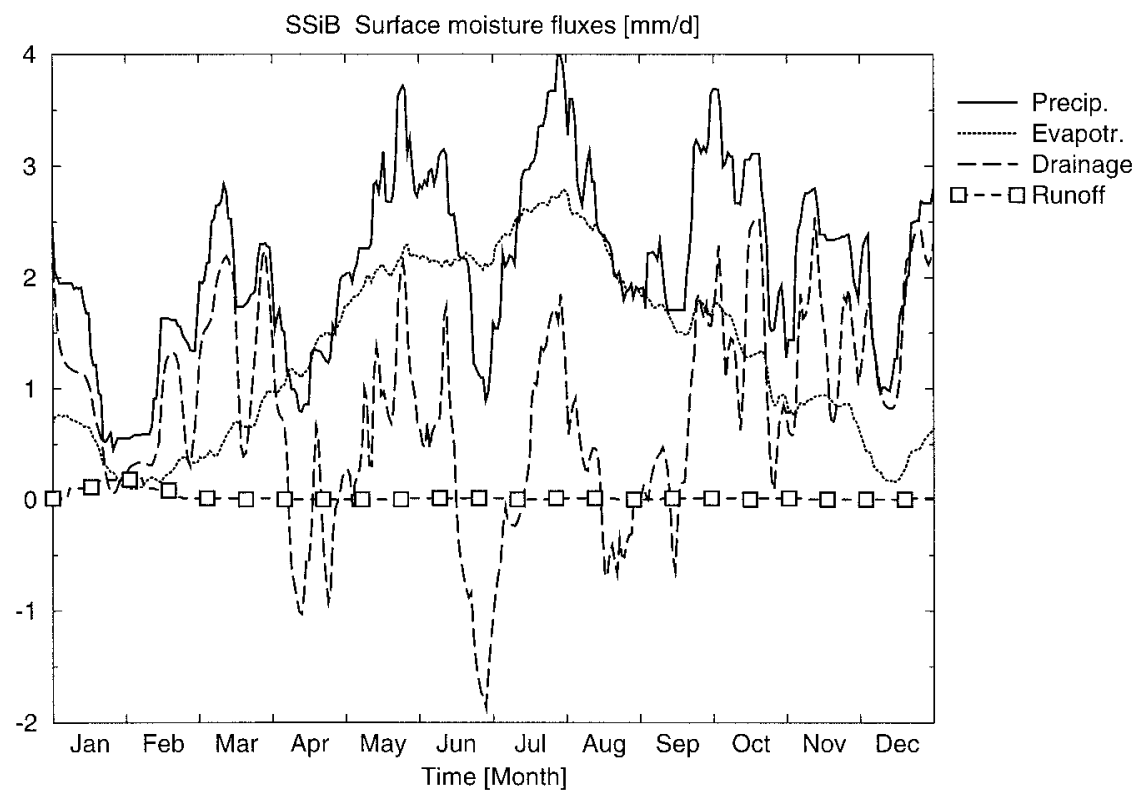

FIG. 12. As in Fig. 10 but for SSiB.

ance simulated by ECHAM or by SECHIBA is more realistic for the Cabauw site because there are no observations available for surface runoff, drainage, and soil water content. According to Beljaars and Bosveld (1997), the Cabauw site is very wet during almost the entire year. Therefore, the annual cycle of the soil moisture simulated by SECHIBA seems to be more realistic than the one by ECHAM (Fig. 9). On the other hand, the high water table at Cabauw is the result of a regulation by a system of ditches. It is likely to observe an annual cycle of soil moisture as the one by ECHAM at a different site in central Europe with flat terrain but without artificial soil moisture regulation.

In Fig. 12, SSiB's surface moisture fluxes are compared to each other. Surface runoff is close to zero throughout the year. This is consistent with the evolution of root zone soil moisture, which is below $70 \%$ of the total water-holding capacity during the entire year (Fig. 9), as surface runoff is mainly produced by infiltration excess. In contrast to ECHAM and SECHIBA, SSiB's root zone drainage shows a pattern similar to that of precipitation. Maxima and minima in the drainage rate are closely related to periods of high and low precipitation, respectively, throughout the year. During the months of low evapotranspiration from November to March, a major part is lost through drainage. But during some periods in April, June, and August-September, when precipitation is reduced but evapotranspiration is high, SSiB also allows negative drainage. This represents an upward motion of soil moisture into the root zone that is possible because the exchange between the soil layers in $\mathrm{SSiB}$ is formulated as a diffusive process. $\mathrm{SSiB}$ is the only one of the three schemes compared in this study that allows recharge from the water table.
A comparison of Figs. 13 and 14 shows the relationship between precipitation, root zone drainage, and soil moisture in SSiB in more detail. In these figures, daily means of the surface moisture fluxes and the relative plant-available soil moisture are compared for a period of 120 days starting from day 91. Precipitation events are often accompanied by downward drainage. Rises of soil moisture are caused by precipitation events or, apparently more often, by upward drainage. Reductions result from evapotranspiration or downward drainage. So in ECHAM and SECHIBA, soil moisture is mainly influenced by precipitation and evapotranspiration, thus showing a distinct annual cycle; however, in $\mathrm{SSiB}$, the root zone drainage obviously plays an important role in the regulation of soil moisture. This is held at an almost constant value. In this context we have to emphasize that SSiB's lowest soil moisture layer was set to saturation during the entire simulation, as requested by the PILPS instructions (cf. Chen et al. 1997). Therefore, the water table stayed at a depth of $1 \mathrm{~m}$, and water supply for the upward water motion from the recharge layer into the root zone was never restricted. This was supposed to represent the conditions at the Cabauw site. This feature may not be representative for SSiB in general but rather site or simulation dependent.

Another feature of the simulation results of SSiB can be identified from the comparison of Figs. 10 and 12. As mentioned before, evapotranspiration in ECHAM is mainly determined by the incoming solar radiation with maxima at the beginning of May and in the first half of July. In contrast to this, evapotranspiration in $\mathrm{SSiB}$ follows more closely the precipitation rate. Both quantities show maxima simultaneously in the second half of May and at the end of July. The annual variations correspond 


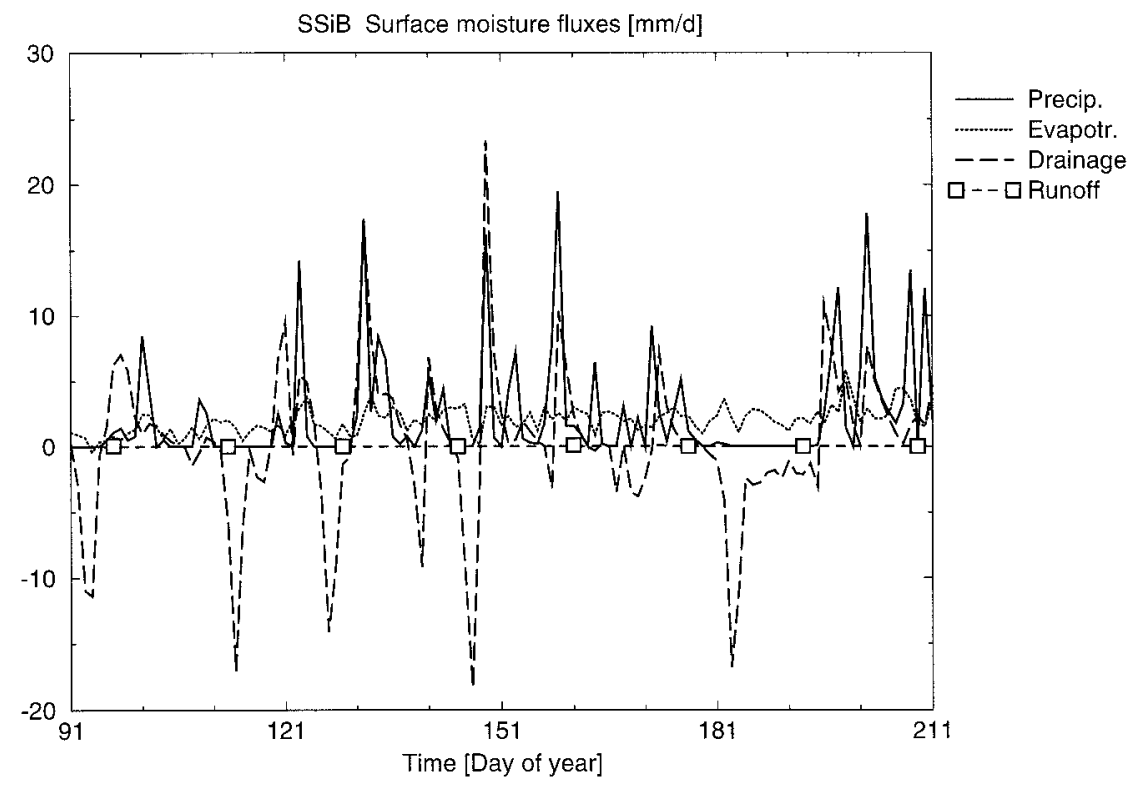

FIG. 13. Evolution of precipitation, evapotranspiration, root zone drainage, and surface runoff during the period from day 91 to day 211 as simulated by SSiB. Shown are unsmoothed daily means.

to each other also during the rest of the year. This different behavior of $\mathrm{SSiB}$ gives rise to differences in the Bowen ratio compared to ECHAM and SECHIBA [cf. discussion in sections $4 \mathrm{a}(1)$ and $4 \mathrm{~b}(1)]$.

The results in Figs. 9-12 show that all three schemes have relatively similar annual cycles of simulated evapotranspiration. However, for the other hydrological components, each of the model simulations can be quite different. The surface runoff and drainage of ECHAM and SECHIBA show moderate variability, while their root zone soil moisture undergoes a pronounced annual cycle. In $\mathrm{SSiB}$, this is the other way around: the root zone soil moisture varies only in a small range, while the root zone drainage shows an annual cycle with a

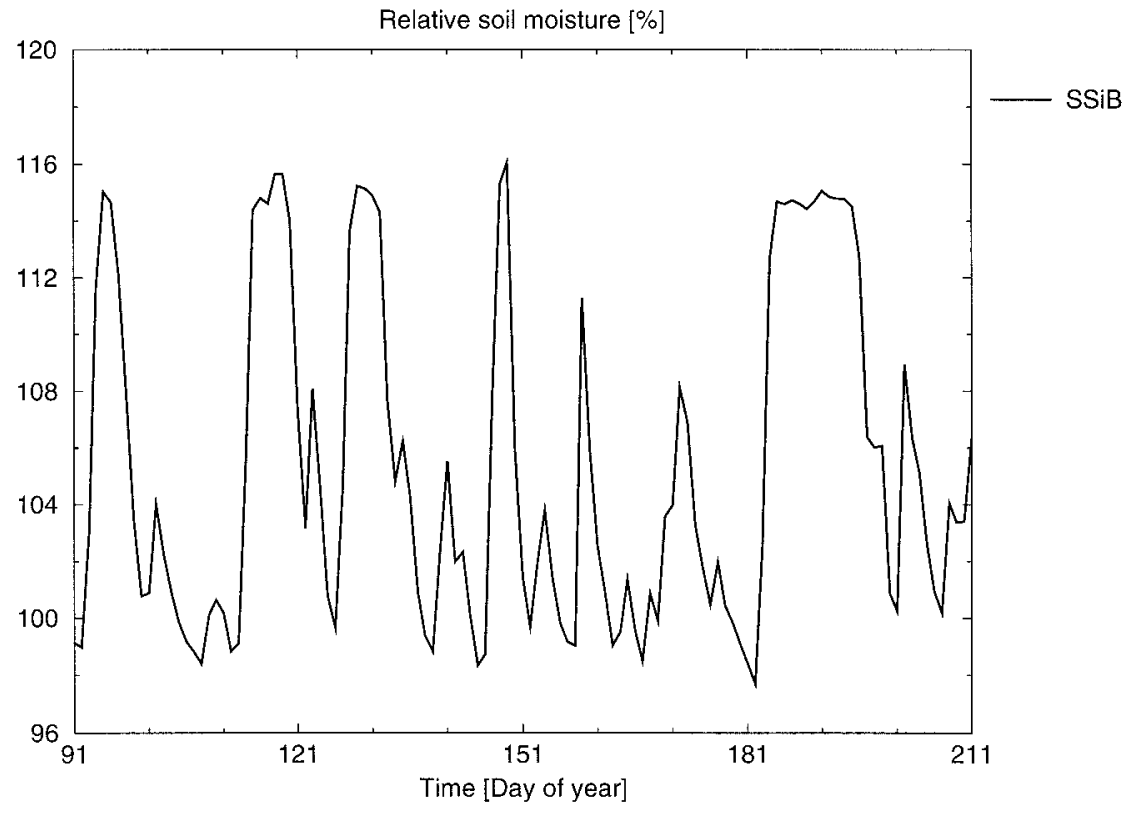

FIG. 14. As in Fig. 13 but for relative plant-available soil moisture in the root zone. 
(a) Surface runoff $[\mathrm{mm} / \mathrm{d}]$

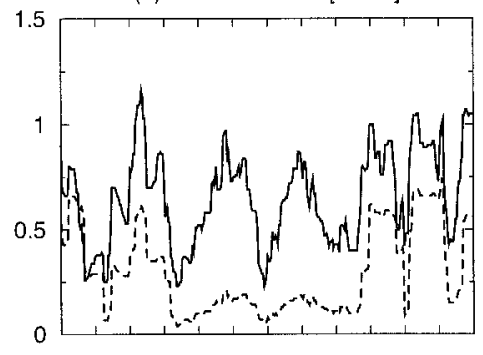

(c) Root zone drainage $[\mathrm{mm} / \mathrm{d}]$

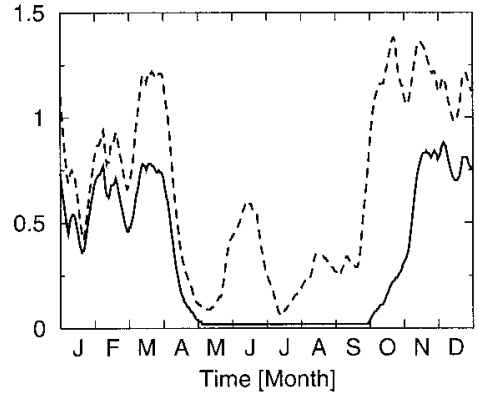

(b) Relative soil moisture [\%]

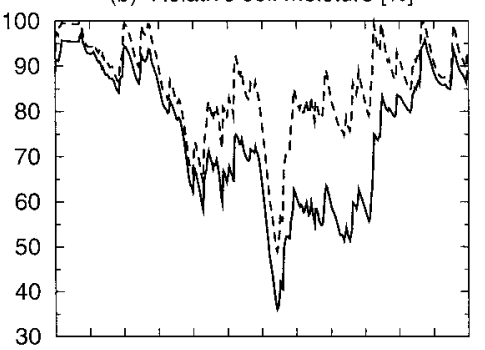

(d) Evapotranspiration $[\mathrm{mm} / \mathrm{d}]$

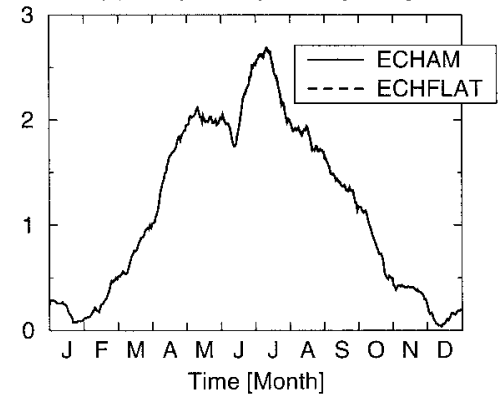

FIG. 15. Comparison of the annual cycles of (a) surface runoff, (b) relative plantavailable soil moisture, (c) root zone drainage, and (d) evapotranspiration simulated by ECHAM and ECHFLAT. The curves were smoothed using a 31-day running mean except in (b).

high variability. Although the models behave very differently internally, they are able to respond to the atmospheric forcing in a similar way.

\section{b. Model sensitivity studies}

In this section, we shall investigate if the underestimation of latent heat flux and overestimation of sensible heat flux in summer is due only to the systematic deficiencies in the parameterizations of the three models or if also a more careful choice of the appropriate parameter values for a realistic representation of the conditions at the Cabauw site can improve the simulations.

\section{1) Surface WAter Balance}

One could argue that due to the Arno scheme, runoff is calculated too high in ECHAM so that there is not enough water left for evapotranspiration. This could explain why evapotranspiration is underestimated. In ECHAM, a structure parameter of $B=0.2$ is used. This is a typical average value representing a moderate steepness of the terrain. Model version ECHFLAT uses a value of $B=0.025$, which indicates a very flat terrain that may be more appropriate for the Cabauw site. Figure 15 shows that in fact surface runoff is reduced in ECHFLAT. More precipitation can infiltrate into the soil so that the relative plant-available soil moisture stays higher during the entire year. But as a result, the drainage rate is increased, in particular, from October to March. The evapotranspiration itself is, however, almost insen- sitive to the variation of the structure parameter. The reason is that the relative plant-available soil moisture in ECHAM and ECHFLAT stays above the threshold value of the critical soil moisture $(33.3 \%$ of the plantavailable soil moisture) all year. Below this value, transpiration will be reduced by soil water stress; above this value, there is no water stress. Little differences in evapotranspiration between ECHAM and ECHFLAT are due to a changed bare soil evaporation that depends on relative soil moisture, but the fraction of bare soil in the grid area is very small. Therefore, this is not a way to improve the simulated annual cycle of latent heat flux for this particular site simulation.

Figure 16 shows the annual evolution of latent heat flux as a result of a changed minimum stomatal resistance $r_{\text {st0 }}$ (model version ECHEVAP) and maximum canopy water content $W_{\text {Imax }}$ (version ECHWL). A reduction of $r_{\text {st0 }}$ and/or an increase of $W_{\text {lmax }}$ gives higher evapotranspiration and lower sensible heat flux (not shown). The sensitivity to $r_{\text {st } 0}$ is greater than to $W_{\operatorname{lmax}}$. The reason is that $r_{\text {st } 0}$ determines the stomatal resistance that controls transpiration, which is the major component of the latent heat flux in the simulations. This is illustrated by Fig. 17, which shows the contributions of snow sublimation, canopy evaporation, transpiration, and bare soil evaporation to the total latent heat flux for ECHAM. The increase of the total latent heat flux in ECHWL in comparison to ECHAM is mainly due to an enhanced canopy evaporation, while the transpiration is reduced (not shown).

As seen in Fig. 16, latent heat flux (as computed from 


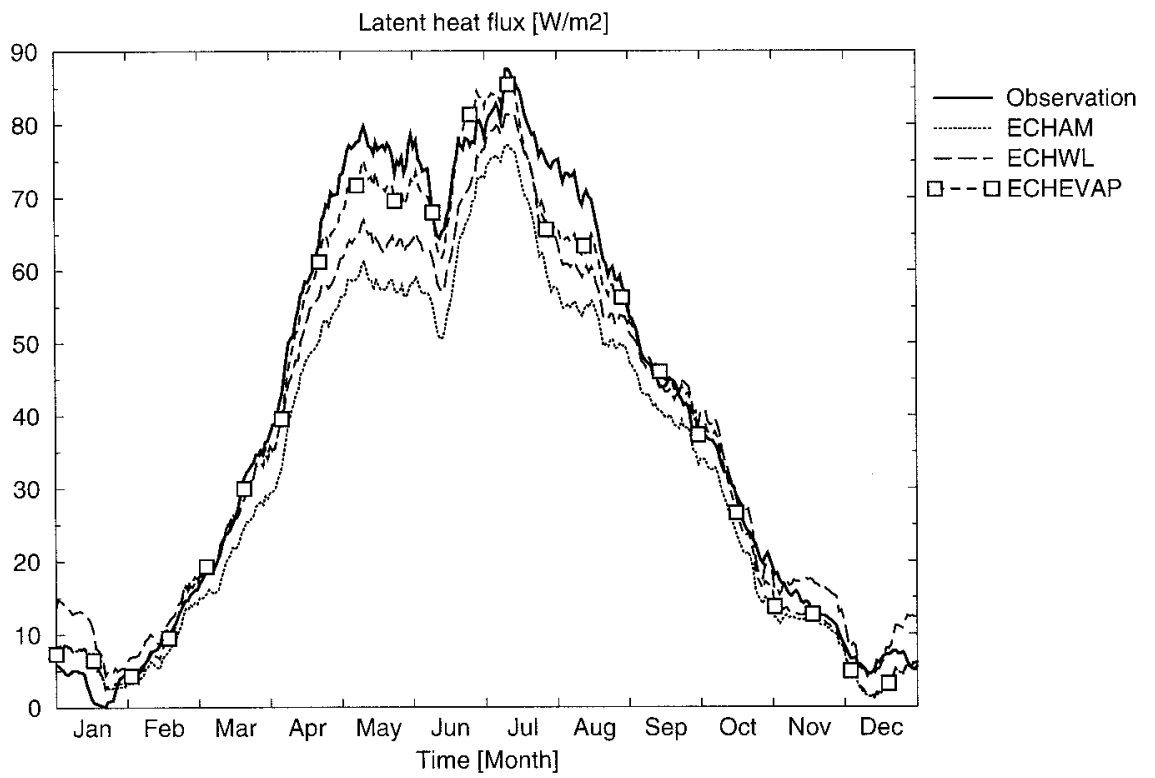

FIG. 16. Annual cycle of latent heat flux as observed at Cabauw compared to the results of the models ECHAM, ECHWL, and ECHEVAP. The curves were smoothed using a 31-day running mean.

the ECHAM scheme) can be improved by prescribing a more appropriate stomatal resistance for the Cabauw ground cover than was specified in the PILPS study initially. The PILPS instructions specified the constant $c$ and the leaf area index (LAI) from which the stomatal resistance is computed (cf. section 2). In the original $\mathrm{SiB}$ scheme (Sellers et al. 1986), from which the stomatal resistance formulation in ECHAM was derived, the stomatal resistance of the standard ground cover (biome type 7) is calculated using a value of $c=110$

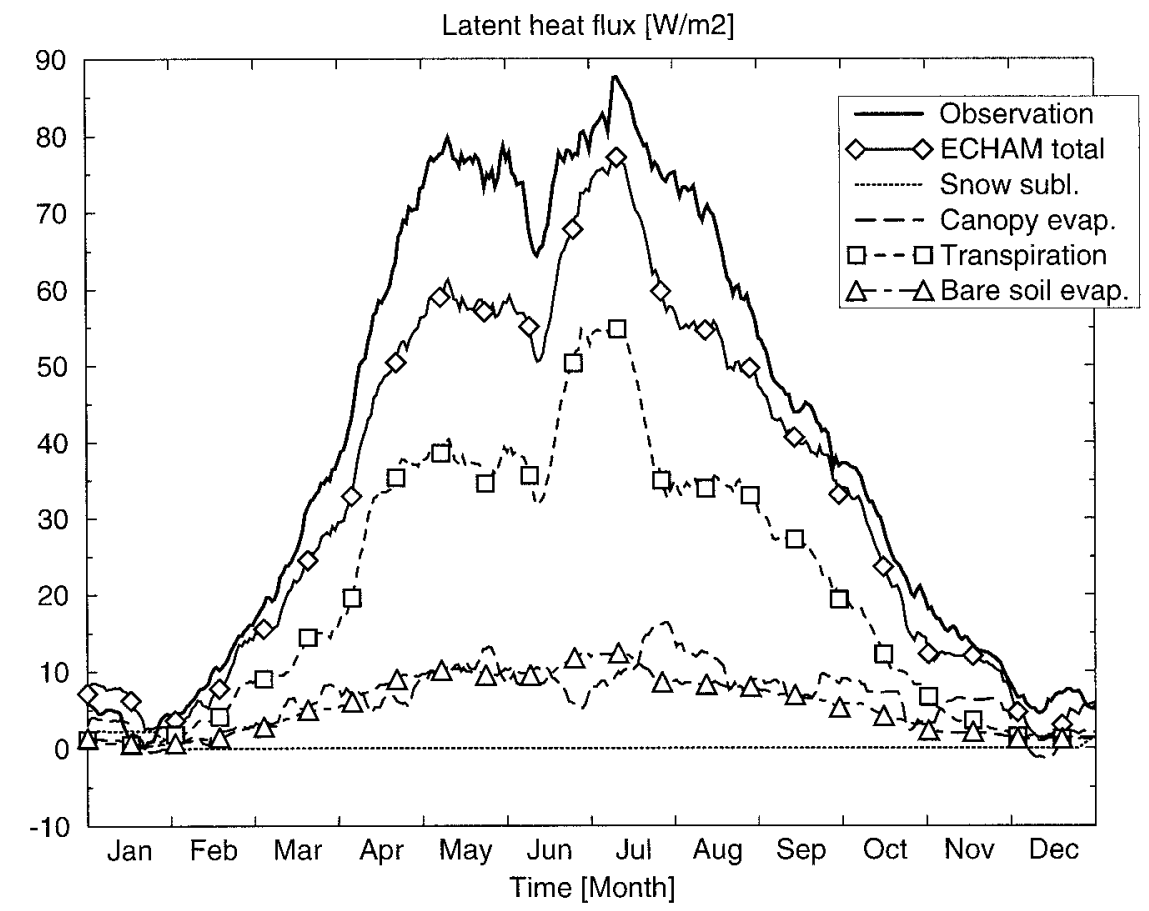

FIG. 17. Contributions of snow sublimation, canopy evaporation, transpiration, and bare soil evaporation to the total latent heat flux for ECHAM compared to the Cabauw observed latent heat flux. The curves were smoothed using a 31-day running mean. 


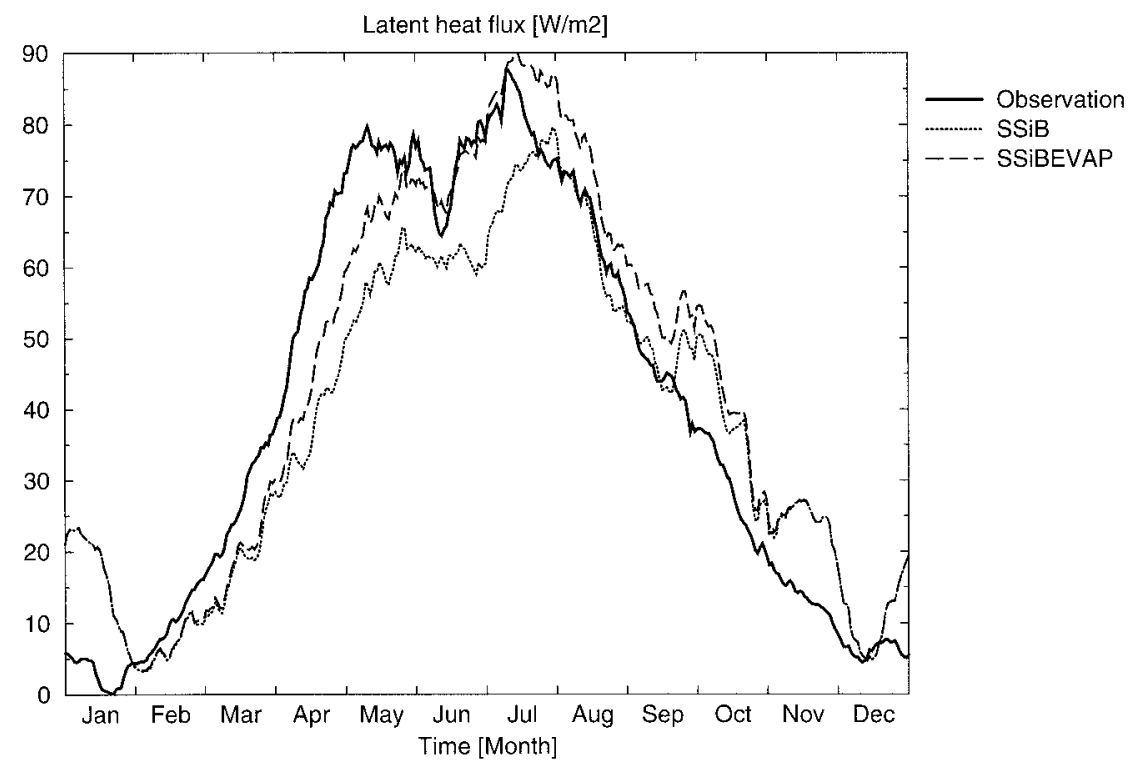

FIG. 18. Annual cycle of latent heat flux as observed at Cabauw compared to the results of the models SSiB and SSiBEVAP. The curves were smoothed using a 31-day running mean.

$\mathrm{s} \mathrm{m}^{-1}$. This biome type was assumed to be appropriate for the Cabauw site. On the other hand, Dorman and Sellers (1989) indicate a different biome type for the location of Cabauw in their global dataset (i.e., broadleaf-deciduous trees with winter wheat, biome type 12). The ground cover part of this biome type has a value of $c=25 \mathrm{~s} \mathrm{~m}^{-1}$. At Cabauw, this ground cover would be appropriate to match the observations. Koster (1995, personal communication) reports that the land surface scheme MOSAIC (Koster and Suarez 1992) gives better results when using the parameter set of this biome type. MOSAIC has a formulation of stomatal resistance similar to SiB. The ECHAM3 standard model uses the combination of LAI $=4$ and $c=100 \mathrm{~s} \mathrm{~m}^{-1}$ for all land points in the global GCM covered with vegetation. The PILPS instructions require a major change to LAI = 1.3 (annual mean) for the Cabauw site but specify only a small change to $c=110 \mathrm{~s} \mathrm{~m}^{-1}$. As it uses an algorithm different from the original $\mathrm{SiB}, \mathrm{ECHAM}$ requires a consistent modification of the $c$ parameter in order to operate in a realistic way. The scheme gives best results for latent heat flux if a value of $c=40 \mathrm{~s} \mathrm{~m}^{-1}$ is chosen, as is shown in Fig. 16 for model version ECHEVAP. For an incoming solar radiation of $900 \mathrm{~W} \mathrm{~m}^{-2}$, which is about the maximum value at the Cabauw site, the minimum stomatal resistance $r_{\text {sto }}$ in model version ECHAM is $95 \mathrm{~s} \mathrm{~m}^{-1}$, while it is $41 \mathrm{~s} \mathrm{~m}^{-1}$ in version ECHEVAP. The latter value compares very well with the observations of Russel (1980), which show surface resistance values of $40 \mathrm{~s} \mathrm{~m}^{-1}$ for a well-watered pasture.

Figure 18 compares the annual evolution of the latent heat flux as observed at Cabauw and the simulations of $\mathrm{SSiB}$ and the slightly modified model version SSiBEVAP. In SSiBEVAP, a parameter value of $c=25 \mathrm{~s}$ $\mathrm{m}^{-1}$ is used (for reasons mentioned before). The value of the albedo computed by the model became lower than the value of 0.25 prescribed by PILPS. Therefore, in SSiBEVAP, the albedo was adjusted to fit as closely as possible 0.25 for nonsnow-covered conditions. With these modifications, the model's variations of evapotranspiration in the summer are in better agreement with the observations and ECHAM and SECHIBA. In particular, the simulation better meets the observed local minimum in June and the maximum in July. This seems to confirm the results of Koster, as mentioned before. Why the evapotranspiration in SSiBEVAP in autumn and winter still follows the precipitation rate, such as $\mathrm{SSiB}$ does during the entire year, is not clear at this stage and is currently under investigation. In this context the root zone drainage seems to be important as it plays a major role in the regulation of soil moisture and is also likely to affect the evapotranspiration (cf. discussions in section 4a2 and Xue et al. 1996).

Sensitivity studies similar to the one conducted with ECHEVAP have shown that SECHIBA's latent heat flux also gets very close to the observations when the minimum stomatal resistance is reduced (V. Quiniou 1995, personal communication).

\section{2) Surface ENERGy BALANCE}

In the two modified versions of ECHAM that are presented in this section, [ECHTEMP and ECHVARI (cf. Table 1)] a changed parameter value of $c=40 \mathrm{~s}$ $\mathrm{m}^{-1}$ as in ECHEVAP is used because, as in the section before, this value was found to be more appropriate for the Cabauw site. We use this value in these further tests because a more realistic simulation is expected. The 


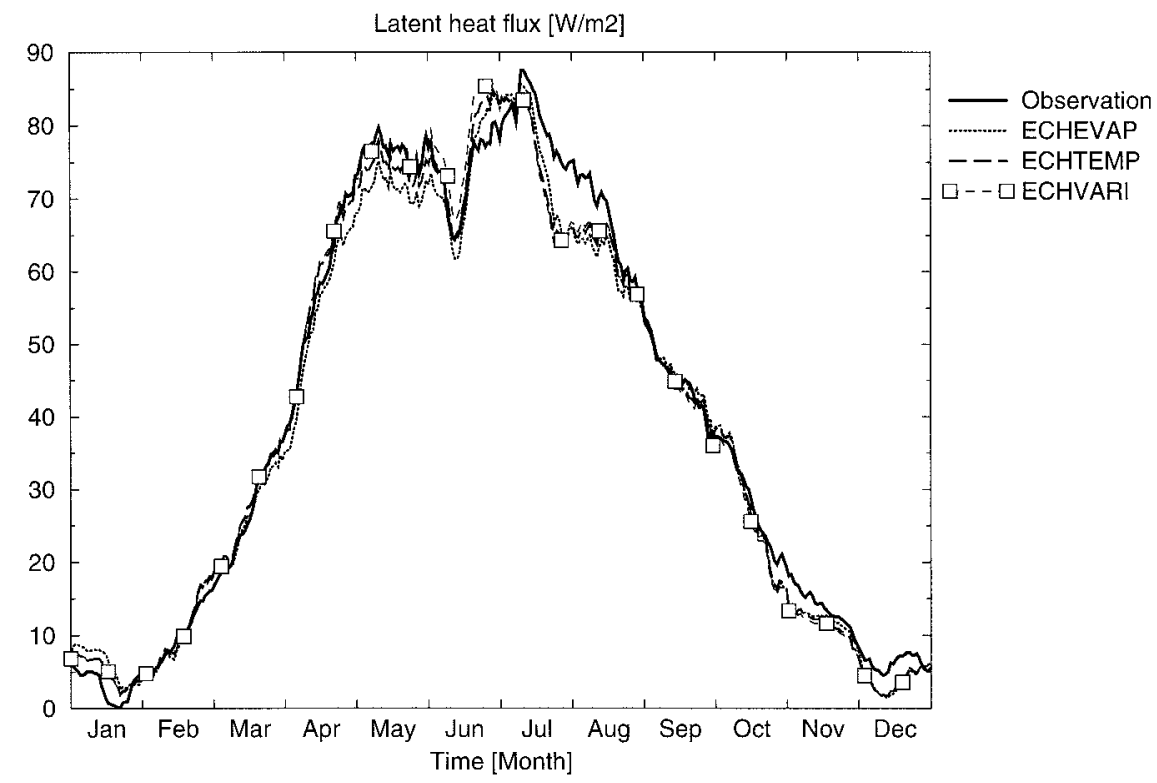

FIG. 19. Annual cycle of latent heat flux as observed at Cabauw compared to the results of the models ECHEVAP, ECHTEMP, and ECHVARI. The curves were smoothed using a 31-day running mean.

temperature top soil layer has an inertia that is due to the discretization of the soil layers in ECHAM. For this reason, the ground heat flux tends to be too large in ECHAM (cf. section 4a). This behavior is also characteristic for the earlier version of the ECMWF scheme and is documented by Betts et al. (1993). As a consequence, there is not enough energy left for the turbulent surface fluxes. This is obvious, for example, for ECHEVAP in the summer when the sum of simulated latent and sensible heat fluxes is less than observed (cf. Figs.
19 and 20). A reduction of the soil thermal conductivity $\lambda$ (model version ECHTEMP) results in a decreased ground heat flux and consequently enhances the amplitude of the diurnal variations of the surface soil temperature (see Fig. 21). The simulated surface temperature gets closer to the observed effective radiative surface temperature, even closer than in SSiB and SECHIBA (cf. Fig. 5). This reduces the deviations of the simulated sensible heat flux, especially in summer. But the feature remains that the diurnal evolution of the

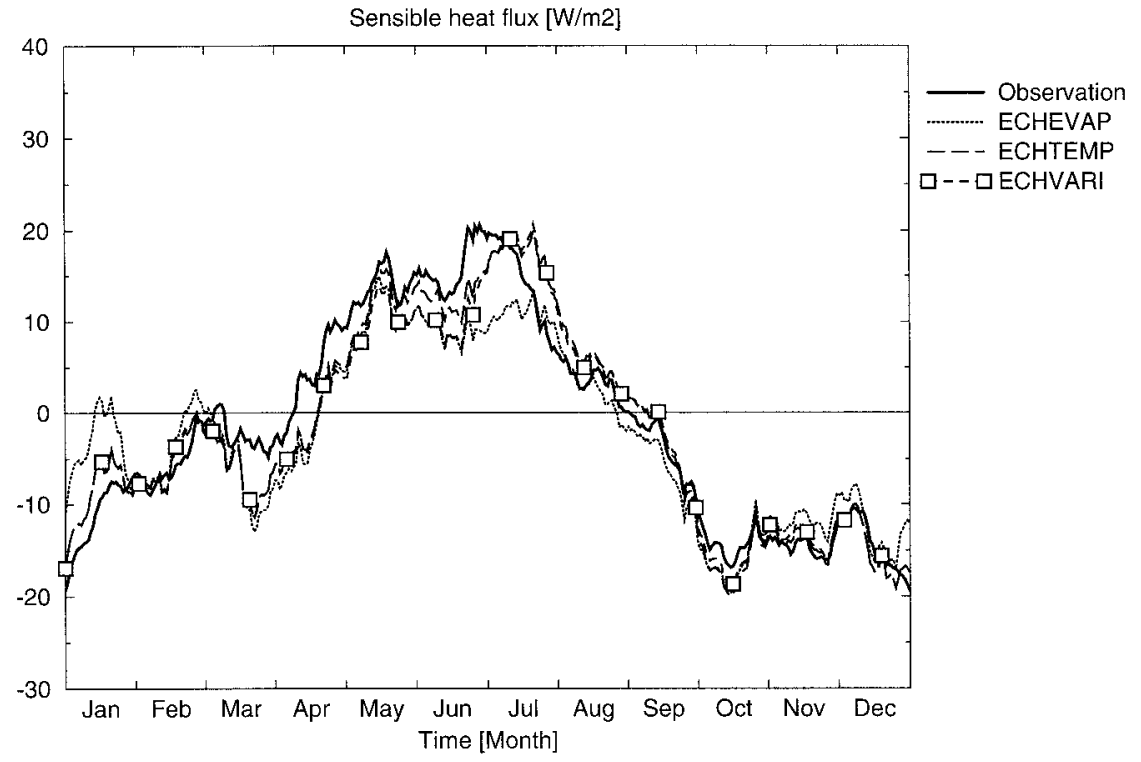

FIG. 20. As in Fig. 19 but for sensible heat flux. 


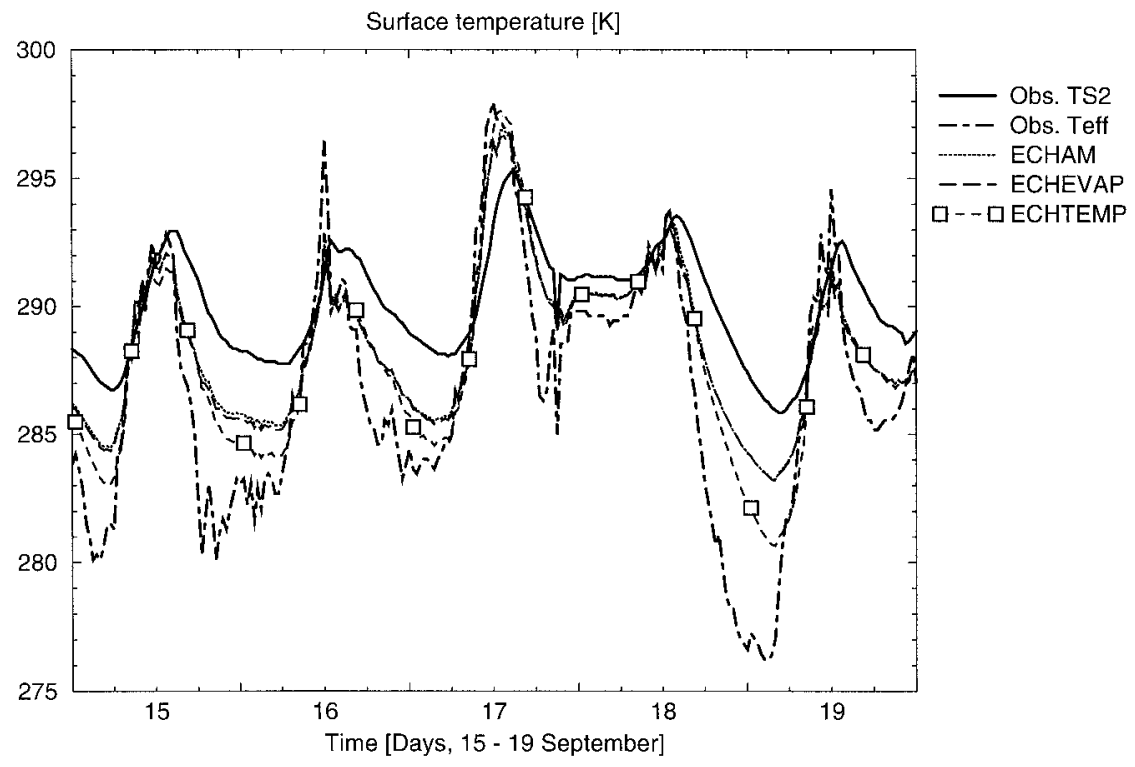

FIG. 21. Diurnal cycles of soil temperature $T_{S^{2}}$ measured at 2-cm depth and observed surface radiative (effective) temperature $T_{\text {eff }}$ from 15 to 19 September compared to the surface temperatures as simulated by ECHAM, ECHEVAP, and ECHTEMP. The observations were made at Cabauw.

simulated surface temperature is delayed in phase compared to the observed $T_{\text {eff }}$ (cf. Fig. 21). Due to the model structure, this has to be expected. This can only be improved by changing the model structure, for example, by introducing a near-surface soil or vegetation layer with a small response time or a so-called skin temperature, as in Viterbo and Beljaars (1995). SSiB makes use of an independent canopy temperature, and SECHIBA tries to better represent the soil temperature profile; in fact, both models show a closer phase relation to the observed effective temperature than ECHAM (Fig. 5). Nevertheless, ground heat flux is closer to the observed in ECHTEMP (Fig. 22) and thus allows a more realistic partitioning of surface total net radiation into ground heat flux and turbulent surface fluxes.

The values that have been chosen for the soil thermal conductivity $\lambda$ correspond to the cases of wet soil $(\lambda=$ $2 \mathrm{~W} \mathrm{~K}^{-1} \mathrm{~m}^{-1}$ for ECHEVAP $)$ and drier soil $(\lambda=1 \mathrm{~W}$

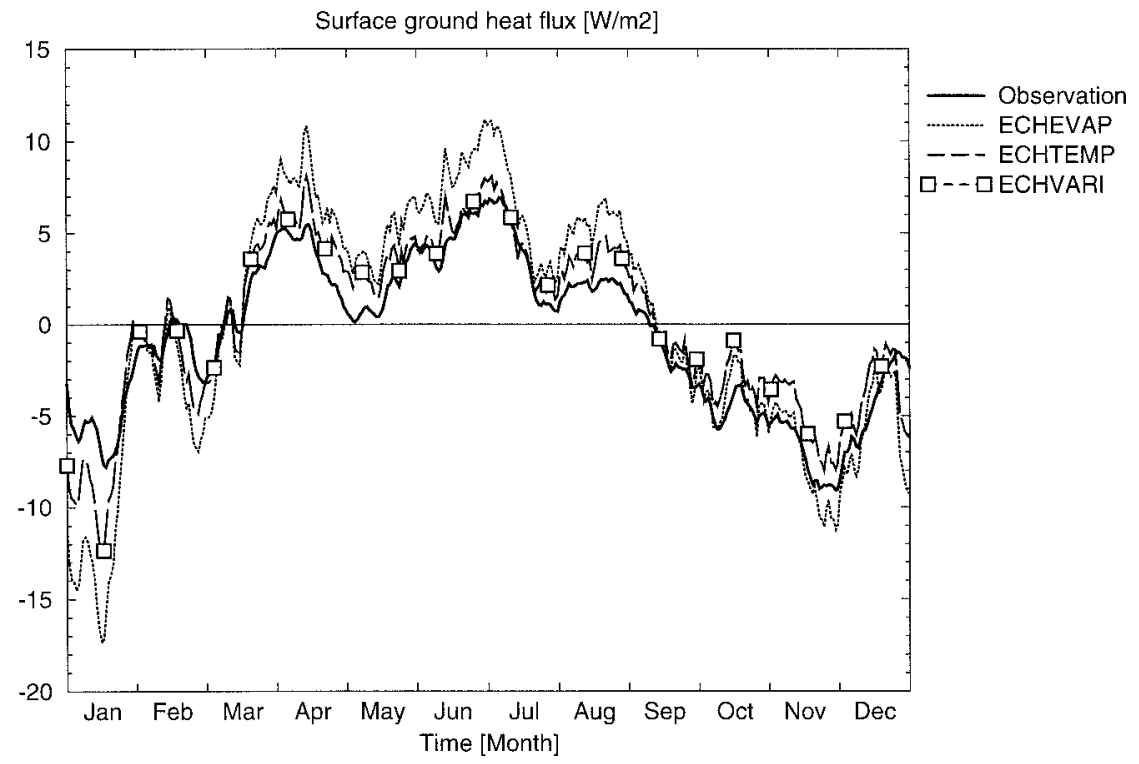

FIG. 22. As in Fig. 19 but for surface ground heat flux. ECHTEMP and ECHVARI show almost identical evolutions. 
$\mathrm{K}^{-1} \mathrm{~m}^{-1}$ for ECHTEMP). Beljaars and Bosveld (1997) show an annual time series of daily values of $\lambda$ that they derived from the Cabauw observations. Their results suggest that $\lambda$ follows a seasonal cycle with higher values in winter and lower in summer. They compare their results to typical values tabulated by Hillel (1982), which cover a similar range as the values used in the different model versions of ECHAM. At about $0.8 \mathrm{~W}$ $\mathrm{K}^{-1} \mathrm{~m}^{-1}$, the "observed" $\lambda$ given by Beljaars and Bosveld (1997) is systematically lower. At the time of writing, they were not able to give a reason for this behavior. The standard value of $\lambda$ used in the ECHAM3 GCM at Cabauw is $1.8 \mathrm{~W} \mathrm{~K}^{-1} \mathrm{~m}^{-1}$, and in the ECHAM4 GCM $1.7 \mathrm{~W} \mathrm{~K}^{-1} \mathrm{~m}^{-1}$. The value of $\lambda$ used in ECHAM may also be compared to the range of values of $\lambda$ in the CLASS scheme, where soil thermal conductivity depends on soil moisture (Verseghy 1991). During annual cycle simulations with CLASS for PILPS, the interactively computed $\lambda$ varied in the range between $1.5 \mathrm{~W}$ $\mathrm{K}^{-1} \mathrm{~m}^{-1}$ (wet soil) and $1.1 \mathrm{~W} \mathrm{~K}^{-1} \mathrm{~m}^{-1}$ (drier soil) (D. Verseghy 1995, personal communication). Figures 19, 20 , and 22 show that in the summer, when the soil gets drier, the simulated latent, sensible, and ground heat fluxes in ECHTEMP are closer to the observations than in ECHEVAP, or both model simulations are almost similar. This may be seen as an indication that the simulation results are expected to be closer to the observations when taking the dependence of the soil thermal conductivity on soil moisture into consideration.

It should be emphasized that the sensitivity study with model version ECHTEMP does not imply that an exact agreement of the simulated surface temperature $T_{S}$ of ECHTEMP and the observed radiative temperature $T_{\text {eff }}$ is desired. Due to the model structure, $T_{S}$ is the soil temperature of the top $6.5 \mathrm{~cm}$. The study shall only show that, if the interface variable of the land surface scheme to the atmosphere, the surface temperature, is closer to the observed $T_{\text {eff }}$, the ground heat flux and latent and sensible heat fluxes are closer to the observations.

If a time-varying LAI and vegetation ratio are used in ECHAM (as in version ECHVARI), the vegetation effect on evapotranspiration is expected to be represented more accurately than by constant values. Figure 19 shows that the simulated latent heat flux in ECHVARI is even closer to the observation in May than in ECHTEMP. But in June, it is overestimated. Correspondingly, sensible heat flux is underestimated during the same period (cf. Fig. 20). But in general, the simulated turbulent fluxes are not very different in ECHTEMP and ECHVARI for this site. The reason is that two opposing effects tend to neutralize each other when the parameters are changed. The increase of the vegetation ratio in May compared to the annual mean (cf. Fig. 2) reduces the bare soil part of the grid square and thus reduces total evapotranspiration. This is due to the fact that in ECHAM daily evapotranspiration from a certain area is lower if it is covered with vegetation instead of bare soil, if the soil is relatively wet. On the other hand, the increase of the LAI enhances transpiration.
For this site and biome type it seems appropriate to use constant values for the parameters mentioned above. But for different biome types with more pronounced annual cycles of these parameters (like deciduous trees), it is expected that a more realistic representation of the vegetation, provided by time-varying values rather than constant parameter values, gives results, for example, for the energy fluxes, closer to the observations. Future model development will incorporate this representation.

\section{Conclusions}

The three land surface schemes-ECHAM, SSiB, and SECHIBA-were developed for use in general circulation models. In this study, results from off-line simulations are presented where the schemes were driven by identical atmospheric data extracted from the $\mathrm{Ca}$ bauw observational dataset of 1987 . The energy and water cycle of the models were compared, and the quantities of the energy cycle were validated against the Cabauw data. Additional studies were performed with the schemes to test the sensitivity to certain parameters and to improve model behavior.

The three models are very different in their structures but, nevertheless, they simulate similar annual cycles of surface temperature and total net radiation. The results are consistent with the Cabauw observations. Differences between the models are more obvious when considering the turbulent heat fluxes regarding amplitude as well as phase. In ECHAM and SECHIBA, evapotranspiration is mainly determined by incoming solar radiation. In $\mathrm{SSiB}$, evapotranspiration rather seems to follow the precipitation rate. However, on an annual timescale, the simulated evapotranspiration of all three models is relatively similar in the Cabauw experiments. But for the other hydrological components, such as surface runoff and drainage and the variations of root zone soil moisture, the model simulations are quite different. This is due to different philosophies of the models.

It is also shown that a model with a relatively simple soil hydrology like ECHAM, only using one soil moisture reservoir, can accurately reproduce the observed latent heat flux at Cabauw. But this requires a careful choice of the appropriate parameter values characteristic for the site to be used. It was found that the annual cycles of the turbulent heat fluxes in ECHAM, SSiB, and SECHIBA are very sensitive to the surface resistance. If a value for the minimum stomatal resistance that is appropriate for the site is chosen, simulated latent and sensible heat fluxes are close to the observations. ECHAM shows deficiencies in modeling the diurnal variations of surface temperature and ground heat flux. This is due to the fact that the temperature of the top soil layer, which has a depth of $6.5 \mathrm{~cm}$, is used for computing the surface energy fluxes. This may be improved by introducing a skin temperature formulation [see also Viterbo and Beljaars (1995) who report on the improvement of the ECMWF land surface scheme by 
the implementation of a skin temperature]. Due to their model formulations, SSiB and SECHIBA capture the observed diurnal variations of the surface temperature marginally better. Therefore, it can be concluded that the simulation results of the three models are consistent with the model structures.

The soil at the Cabauw site is almost saturated most of the year. A model intercomparison, as the one reported here, should be repeated for a more arid climate with a dry period of a few weeks or months during summer. It would also be desirable to use an observational dataset for validation including measurements of the components of the hydrological cycle such as surface runoff, root zone drainage, and soil moisture. A principal drawback of off-line simulations is that feedback effects between the land surface and the atmosphere are excluded. Therefore, the next step after having studied the general model behavior in off-line experiments will be the intercomparison of one-dimensional and global coupled land-atmosphere models. In this context, the method of computing the surface temperature, which is discussed in this study for the three schemes, and the coupling technique will be important issues.

Acknowledgments. We wish to thank A. HendersonSellers, T. H. Chen, A. J. Pitman, and other members of the group at Macquarie University, Sydney, Australia, who are organizing the Project for Intercomparison of Land-surface Parameterization Schemes (PILPS). We acknowledge The Royal Netherlands Meteorological Institute (KNMI) for providing the Cabauw observational data. We are very grateful to A. C. M. Beljaars who gave valuable input to this work. We would like to extend our gratitude to R. D. Koster, X. Liang, D. L. Verseghy, and P. Viterbo for many helpful discussions. This work was supported by the European Economic Community under Contract EV5V-CT92-0125.

\section{REFERENCES}

Beljaars, A. C. M., and P. Viterbo, 1994: The sensitivity of winter evaporation to the formulation of aerodynamic resistance in the ECMWF model. Bound.-Layer Meteor., 71, 135-149.

_ , and F. C. Bosveld, 1997: Cabauw data for the validation of land surface parameterization schemes. J. Climate, 10, 1172 1193.

Betts, A. K., J. H. Ball, and A. C. M. Beljaars, 1993: Comparison between the land surface response of the ECMWF model and the FIFE-1987 data. Quart. J. Roy. Meteor. Soc., 119, 975-1001.

Chen, T. H., and Coauthors, 1997: Cabauw experimental results from the Project for Intercomparison of Land-surface Parameterization Schemes. J. Climate, 10, 1194-1215.

Dooge, J. C. I., M. Bruen, and A. Dowley, 1994: Spatial variability of land surface processes. Tech. Rep. LSP./94/19, 145 pp. [Avail- able from Centre for Water Resources Research, University College Dublin, Earlsfort Terrace, Dublin 2, Ireland.]

Dorman, J. L., and P. J. Sellers, 1989: A global climatology of albedo, roughness length, and stomatal resistance for atmospheric general circulation models as represented by the Simple Biosphere model (SiB). J. Appl. Meteor., 28, 833-855.

Driedonks, A. G. M., H. van Dop, and W. Kohsiek, 1978: Meteorological observations on the $213 \mathrm{~m}$ mast at Cabauw in the Netherlands. Preprints, Proc. Fourth Symp. Meteorological Observations and Instrumentation, Denver, $\mathrm{CO}$, Amer. Meteor. Soc., 41-46.

Ducoudré N. I., K. Laval, and A. Perrier, 1993: SECHIBA, a new set of parameterizations of the hydrologic exchanges at the landatmosphere interface within the LMD atmospheric general circulation model. J. Climate, 6, 248-273.

Dümenil, L., and E. Todini, 1992: A rainfall-runoff scheme for use in the Hamburg climate model. Advances in Theoretical Hydrology, J. P. O’Kane, Ed., European Geophysical Society Series on Hydrological Sciences, Vol. 1, Elsevier, 129-157.

Hagemann, S., and L. Dümenil, 1996: Development of a parameterization of lateral discharge for the global scale. MPI Rep. 219, $32 \mathrm{pp}$. [Available from Max-Planck-Institut für Meteorologie, Bundesstr. 55, 20146 Hamburg, Germany.]

Henderson-Sellers, A., Z.-L. Yang, and R. E. Dickinson, 1993: The Project for Intercomparison of Land-surface Parameterization Schemes (PILPS). Bull. Amer. Meteor. Soc., 74, 1335-1349.

Hillel, D., 1982: Introduction to Soil Physics. Academic Press, 364 pp.

Koster, R. D., and M. J. Suarez, 1992: Modeling the land surface boundary in climate models as a composite of independent vegetation stands. J. Geophys. Res., 97, 2697-2715.

Louis, J.-F., 1979: A parametric model of vertical eddy fluxes in the atmosphere. Bound.-Layer Meteor., 17, 187-202.

Polcher, J., K. Laval, L. Dümenil, J. Lean, and P. R. Rowntree, 1996: Comparing three land surface schemes used in general circulation models. J. Hydrol., 180, 373-394.

Roeckner, E., and Coauthors, 1992: Simulation of the present-day climate with the ECHAM model: Impact of model physics and resolution. MPI Rep. 93, 171 pp. [Available from Max-PlanckInstitut für Meteorologie, Bundesstr. 55, 20146 Hamburg, Germany.]

Russell, G., 1980: Crop evaporation, surface resistance, and soil water status. Agric. Meteor., 21, 213-226.

Sellers, P. J., Y. Mintz, Y. C. Sud, and A. Dalcher, 1986: A Simple Biosphere Model ( $\mathrm{SiB})$ for use within general circulation models. J. Atmos. Sci., 43, 505-531.

Verseghy, D. L., 1991: CLASS-A Canadian land surface scheme for GCMS. I. Soil model. Int. J. Climatol., 11, 111-133.

Viterbo, P., and A. C. M. Beljaars, 1995: An improved land surface parameterization scheme in the ECMWF model and its validation. J. Climate, 8, 2716-2748.

Warrilow, D. A., A. B. Sangster, and A. Slingo, 1986: Modelling of land surface processes and their influence on European climate. Meterological Office, Tech. Note DCTN 38, 92 pp. [Available from Meteorological Office, London Rd., Bracknell, Berkshire RG12 2SZ United Kingdom.]

Xue, Y., and J. Shukla, 1993: The influence of land surface properties on Sahel climate. Part I: Desertification. J. Climate, 6, 22322245.

_ P. J. Sellers, J. L. Kinter, and J. Shukla, 1991: A simplified biosphere model for global climate studies. J. Climate, 4, 345364.

_ F. J. Zeng, and C. A. Schlosser, 1996: SSiB and its sensitivity to soil properties-A case study using HAPEX-Mobilhy data. Global Planetary Change, 13, 183-194. 